\title{
Long-term patterns of self-reported opioid use, VACS Index, and mortality among people with HIV engaged in care
}

Joëlla W. ADAMS ${ }^{1}$, Yu LI, PhD¹, Declan T. BARRY², Kirsha S. GORDON ${ }^{3,4}$, Robert D. KERNS ${ }^{2,3}$, Benjamin OLDFIELD ${ }^{5}$, Christopher T. RENTSCH ${ }^{3,6}$, Brandon D.L. MARSHALL ${ }^{1}$, and E. Jennifer EDELMAN ${ }^{4,7 *}$

1. Brown University School of Public Health, Department of Epidemiology, Providence, RI

2. Department of Psychiatry, Yale School of Medicine, New Haven, CT

3. VA Connecticut Healthcare Systems, West Haven, CT

4. Department of Internal Medicine, Yale School of Medicine, New Haven, CT

5. Department of Pediatrics, Yale School of Medicine, New Haven, CT

6. Faculty of Epidemiology and Population Health, London School of Hygiene \& Tropical Medicine, Keppel Street, London, UK

7. Center for Interdisciplinary Research on AIDS, Yale School of Public Health, New Haven, CT

${ }^{*}$ Corresponding author

Address: $\quad 367$ Cedar Street, ES Harkness, Suite 401, New Haven, CT, 06510

Tel: $\quad 203.737 .7115$

Email:_ejennifer.edelman@yale.edu

Running head: Trajectories of opioid use \& mortality risk

\section{Declarations}

Funding: This work was supported by the National Institute on Drug Abuse (5R01DA040471-03, R25-DA037190), National Institute on Alcohol Abuse and Alcoholism (U10-AA13566), National Institute of Mental Health (F31-MH114736-01A1), and National Institute of Allergy and Infectious Diseases (T32-Al052074).

Conflicts of Interest: The authors declare that they have no conflict of interest.

Ethics Approval: VACS received approval from the Institutional Review Boards at Yale University, VA Connecticut Healthcare System, and each participating site.

Consent to participate: All participants gave written informed consent.

Consent for publication: Not applicable

Availability of data and material: A de-identified data set can be made available upon written request and approval by VACS leadership.

Code availability: Please request information on code used by notifying corresponding author. 
Authors' contributions: JWA, YL, BDLM, and EJE conceptualized this specific analysis. YL performed the formal analysis. JWA and EJE wrote the resulting manuscript while $\mathrm{YL}$, DTB, KSG, RDK, BO, CTR, and BDLM provided feedback and edits. All authors reviewed and approved submission. 
Title: Long-term patterns of self-reported opioid use, VACS Index, and mortality among people with HIV engaged in care

\begin{abstract}
Longitudinal analyses of opioid use and overall disease severity among people with HIV (PWH) are lacking. We used joint-trajectory and Cox proportional hazard modeling to examine the relationship between self-reported opioid use and the Veterans Aging Cohort Study (VACS) Index 2.0, a validated measure of disease severity and mortality, among PWH engaged in care. Using data from 2002 and 2018, trajectory modeling classified $20 \%$ of 3,658 PWH in low (i.e., lower risk of mortality), $40 \%$ in moderate, $28 \%$ in high, and $12 \%$ in extremely high VACS Index trajectories. Compared to those with moderate VACS Index trajectory, PWH with an extremely high trajectory were more likely to have high, then de-escalating opioid use (adjusted odds ratio [AOR], 95\% confidence interval [CI]: $5 \cdot 17$ [3-19-8.37]) versus stable, infrequent use. PWH who report high frequency opioid use have increased disease severity and mortality risk over time, even when frequency of opioid use de-escalates.
\end{abstract}

Word count: 149/150 limit

MeSH keywords: opioid-related disorders; HIV-1; mortality 


\section{INTRODUCTION}

Opioids, both in the context of prescribed opioids and opioids used without a prescription or in a manner other than prescribed, are increasingly being used by people with HIV (PWH) globally (1). Long-term and high dose opioid use increases risk of accidental and intentional opioid overdose (2) and other adverse health outcomes including cardiovascular effects(3), bloodstream infections (e.g., endocarditis) (4), and death from accidental injury other than overdose (5). Importantly, PWH may be particularly vulnerable to harms associated with opioid use due to the increased prevalence of substance use disorders and mental illness $(6,7)$. In addition, opioids may negatively impact immune function $(8,9)$, interact with antiretroviral medication (10), or cause other harms specific to HIV serostatus. A recent cross-sectional analysis demonstrated that opioid misuse is associated with poor viral control by decreasing antiretroviral (ART) use and adherence (11). While there is a lack of compelling evidence that prescribed opioid use impacts CD4 count (12), less is known on the impact of opioids (regardless of source and reason for use) on an overall measure of disease severity over time.

To our knowledge, no studies have yet examined the impact of longitudinal opioid use on overall disease severity and mortality among PWH. Within this analysis, we examine opioid use and trajectories of the VACS Index 2.0 score ("VACS Index"), a validated and generalizable risk index that measures overall disease severity, over time. The VACS Index incorporates routinely collected biomarkers to provide an overall summary of disease burden (13). Since the VACS Index was introduced in 2013, studies have shown that higher scores indicate an increased risk of all-cause mortality, hospitalization, intensive care admission, and other adverse health outcomes $(14,15)$. To date, while studies have examined the impact of alcohol use (16) and receipt of opioid agonist treatment among patients with opioid use disorder (17) on the VACS Index and mortality, no studies have assessed the relationship between any opioid use and VACS Index among PWH. As PWH are increasingly exposed to opioids long-term, 
particularly in developing countries, there is a need to understand the relationship between opioid use and overall health (1).

Thus, using data on a sample of PWH engaged in care, we sought to characterize longterm patterns of self-reported opioid use and concurrent trajectories of the VACS Index, which accounts for HIV disease progression and changes in biomarkers capturing overall health. We hypothesized that patients with an escalating pattern of self-reported opioid use over time would have poorer mortality prognosis and higher rates of mortality compared to individuals with other patterns of opioid use. Classification of self-reported opioid use trajectories might assist health providers in identifying patients with patterns of use that place them at increased mortality risk.

\section{METHODS}

\section{Overview and Study population}

The Veterans Aging Cohort Study (VACS) is a prospective cohort of U.S. military veterans with HIV and race-, age-, and site-matched HIV-negative controls within Veterans Health Administration care in the following locations: Atlanta, Georgia; Baltimore, Maryland; New York (Bronx and Manhattan); Houston, Texas; Los Angeles, California; Pittsburgh, Pennsylvania; and Washington, D.C. Patient surveys are administered approximately every year and linked to electronic health record information including pharmacy fills/refills, laboratory data (including HIV RNA viral load and CD4+ cell count), and administrative data on health care utilization and diagnostic codes (18). Detailed information regarding the VACS study design and methods has been previously described (18). For this analysis, we included participants if they had an HIV diagnosis and we excluded those missing all self-reported items on opioid use during the study period. VACS received approval from the Institutional Review Boards at Yale University, VA Connecticut Healthcare System, and each participating site. 


\section{Self-reported opioid trajectories}

We created a time-varying variable to capture frequency of self-reported opioid use (regardless of reason or source) using self-reported prescription opioid use and heroin use on every available survey between 2002 and 2018 (19). Consistent with our prior work, prescription opioid and heroin use were evaluated with the following questions: "For each of the following drugs, please mark the box that best indicates how often in the past year you used each drug: ....heroin; prescription painkillers (such as Oxycontin, Vicodin, Percocet)"(19). Response options for all substances included: have never tried, no use in the last year, less than once a month, 1-3 times a month, 1-3 times a week, 4-6 times a week, or every day. The baseline survey in 2002 contained slightly different question wording as it referred to "opioids (heroin, morphine, codeine, opium)" rather than heroin and prescription painkillers separately, and during wave 3 , when these items were also collapsed into one measure. Frequency of selfreported opioid use was defined by whichever opioid (heroin or prescription painkillers) was most frequently used during that survey wave.

\section{Outcome measures}

Our outcome of interest was change in VACS Index 2.0 score ("VACS Index"). The VACS Index was recently updated to incorporate measures of albumin, white blood count, and body mass index (BMI) and use of continuous, rather than categorical or ordinal, biomarker information (20). The VACS Index consists of the following components: age, CD4+ cell count, HIV-1 RNA, hemoglobin, alanine (ALT) and aspartate (AST) transaminases, platelets, creatinine, hepatitis $C$ status, albumin, white blood count, and body mass index (BMI) (20). A five-point increase in the VACS Index is associated with a $30 \%$ increased risk of five year mortality (20). Within this analysis, the VACS Index score was updated for each available survey wave, using laboratory values from dates closest to the participant's reported opioid use, 
and recalculated each time a lab was updated, with components of the VACS Index carried forward up to a year. This time-varying VACS Index score was then used within a joint-trajectory analysis with patterns of self-reported opioid use.

Mortality was assessed as a secondary outcome by identifying VACS participants who died during the study period (2002-2018). Death data was made available through Veterans Health Administration's patient files, the Beneficiary Identification Records Locating System, the Medicare Vital Status file, and the Social Security National Death Index (21).

\section{Covariates}

We considered sociodemographic, clinical, and substance-use related covariates within the multivariable analyses. Sociodemographic variables included: sex at birth, race/ethnicity, educational attainment, marital status, history of housing instability, location of residence, and annual income. Clinical covariates included any history of cancer, anxiety symptoms (evaluated using items from the HIV Symptoms Index), depressive symptom severity (based on scores on the Patient Health Questionnaire-9 [PHQ-9]), and reported level of pain interference over the past four weeks (considered present if self-reported moderate, quite a bit, or extreme pain interference with normal work [including both work outside the home and housework]). We also evaluated prescribed medications by length of prescription (none vs. short-term or $<90$ days supplied vs. long-term or $\geq 90$ days supplied) for the following: benzodiazepines, antidepressants, gabapentinoids, and high ( $\geq 50 \mathrm{mg}$ morphine equivalent daily dose) or lowdosage (<50 mg) prescription opioids using VA pharmacy fill/re-fill data. These prescription medications were found to be associated with opioid trajectory groups in previous analyses and have been associated with mortality risk (22). Substance use covariates included self-reported smoking status, unhealthy alcohol use based on the Alcohol Use Disorders Identification TestConsumption (AUDIT-C) questionnaire scores ( $\geq 3$ for women, $\geq 4$ for men), and self-reported 
cannabis and stimulant (including cocaine) use. Age, hepatitis C virus (HCV) status, HIV RNA viral load, and other biomarkers comprising the VACS Index score were not included as covariates within multivariable joint-trajectory models as they are already accounted for within the score. These covariates were included within the multivariable Cox regression model. A detailed description of covariates and sources is included in Supplemental Table 1.

\section{Statistical analysis}

To characterize concurrent patterns of self-reported opioid use and VACS Index scores over time, we utilized a joint-trajectory modeling approach in which two longitudinal measures were evaluated contemporaneously (23). This semiparametric, group-based mixture modeling approach identified joint self-reported opioid use and VACS Index score trajectories (23). This modeling approach has previously been used to characterize long-term opioid use patterns within the VACS cohort (19). First, the model estimated the trajectories for self-reported opioid use and VACS Index score over time and the conditional probabilities for membership in each combination of trajectories for every individual. Then, the model assigned each individual to the combination of trajectories with the highest probability of membership. The number of trajectory groups and trajectory shapes were determined using model fit statistics, including the Bayesian information criterion (BIC) and the significance of polynomial terms, with the goal of having each trajectory group contain $5 \%$ or more of the total sample (19). Non-random attrition, including missing data due to death, was accounted for using an enhanced modeling approach that modeled attrition simultaneously within the opioid use trajectory as a function of time (24). We used a zero-inflated Poisson outcome distribution for the self-reported opioid use trajectory and a censored normal model for VACS Index scores (with higher scores indicating greater mortality risk). The time scale was follow-up time in years from the date of study enrollment for each participant to death or end of study period (2018). 
Bivariate analysis using Pearson $\mathrm{x}^{2}$ and Wilcoxon rank-sum tests was then used to compare the baseline characteristics of individuals in each VACS Index trajectory group. Because the outcome had more than two levels, we used multinomial logistic regression to estimate the odds of membership in each VACS Index trajectory, conditional on membership in each self-reported opioid use trajectory, controlling for selected covariates. The final multivariable model was chosen using a manual backwards selection procedure that began with covariates with a $p$-value $<0.05$ in bivariate analyses and evaluated model fit using the Akaike information criterion.

To estimate the impact of opioid trajectories on all-cause mortality, we first used unadjusted Kaplan-Meier survival curves and the log-rank test while stratifying by self-reported use of opioids trajectory groups. We then used Cox proportional hazards regression to estimate adjusted hazard ratios related to all-cause mortality, including accidental, self-inflicted, and violence-related deaths. Included variables were selected from bivariable analyses and were found to meet the proportional hazards assumption for Cox regression models. Finally, sensitivity analyses were performed omitting prescribed opioid receipt as a covariate to assess if our findings were driven by opioid use for palliative care. All analyses were performed in SAS 9.4 (SAS Institute Inc., Cary, North Carolina, USA).

\section{RESULTS}

\section{Participant characteristics}

Among 3,684 VACS participants with HIV, we excluded individuals missing all selfreported items on opioid use across survey waves $(n=26)$ for a final analytic sample of 3,658 . In total, we had 22,684 person-years of observation with a median of $4($ IQR: 2,6$)$ surveys available per person. Overall, most of our analytic sample was comprised of older African American men living in urban areas and making less than $\$ 50,000$ per year. The majority had received ART and nearly half were virally suppressed (<400 copies $/ \mathrm{mL}$ ) at baseline (Table 1). 


\section{VACS Index 2.0 trajectories}

Joint-trajectory modeling identified four distinct VACS Index trajectories: 1) low; 2) moderate (reference group); 3 ) high; and 4) extremely high. Approximately $20 \%$ of participants were classified within the low (i.e., lower risk of mortality), $40 \%$ in moderate, $28 \%$ in high, and $12 \%$ in extremely high VACS Index trajectories (see trajectories over study period, Supplemental Figure 1). Sociodemographic characteristics at baseline were significantly different for patients within the high or extremely high VACS Index score trajectories, compared to low or moderate: they were older, were more likely to be non-white, were more likely to have a history of housing instability, and have a lower annual income compared to patients within the other VACS Index trajectory groups. In addition, these individuals had a lower CD4+ cell count, were less likely to be virally suppressed, more likely to have HCV, and higher levels of pain interference and depressive symptom severity at baseline. They were more likely to have received prescribed opioids and more likely to be classified within the high, then de-escalating opioid use trajectory (Table 1). Note that the trajectory modeling procedure utilizes the best fitting mean value for the VACS Index score and that individual variation over time was possible as demonstrated by the standard deviation in VACS Index scores within Table 1 and the error bars in Supplemental Figure 1. A majority of participants within these higher VACS Index trajectories died during follow-up: $88 \%$ of those within the extremely high and $53 \%$ within the high trajectory compared to $10 \%$ within the low VACS trajectory.

\section{Self-reported opioid use trajectories}

Joint-trajectory modeling identified four distinct opioid use trajectories: 1) no use; 2) stable and infrequent; 3) escalating; and 4) high, then de-escalating opioid use. A quarter of participants were grouped within the no use trajectory, $62 \%$ with stable and infrequent use, $8 \%$ 
with escalating use, and $5 \%$ with high, then de-escalating use. Figure 1 examines the relationship between membership in each opioid use trajectory and VACS trajectory group. Nearly a third $(30 \%)$ of participants within the no lifetime use of opioid trajectory were within the low VACS trajectory compared to only $5-6 \%$ of those within the de-escalating and escalating opioid use trajectories. Most individuals classified as belonging to the escalating and deescalating opioid use trajectories were within the high or extremely high VACS score trajectories. The high, then de-escalating opioid use trajectory group had the highest percentage of individuals with extremely high VACS scores (31\%).

\section{Factors associated with VACS trajectories}

Multinomial logistic regression was used to compare one category of the outcome (i.e., VACS trajectory group) to the other VACS trajectory groups within levels of the exposure (i.e., opioid use trajectory) and selected covariates. The moderate VACS trajectory group was selected as the reference group as this grouping contained the most participants. When examining factors associated with membership within the VACS trajectory groups, we found that sociodemographic as well as HIV clinical factors and substance use had significant impact on the likelihood of group membership (Table 2). For example, African American individuals had twice (adjusted odds ratio, AOR $[95 \% \mathrm{Cl}]=1.91[1.32-2 \cdot 77]$ ) the odds of membership within the extremely high VACS group vs. the moderate VACS trajectory compared to white individuals. Participants making less than $\$ 12,000$ in annual income and with less education were more likely to be within the high or extremely high VACS trajectory groups. Opioid use trajectories were significantly associated with VACS trajectory membership. For example, individuals with high, then de-escalating opioid use were more likely to be within the extremely high VACS trajectory group $(\mathrm{AOR}[95 \% \mathrm{Cl}]=5 \cdot 17[3 \cdot 19-8 \cdot 37])$ compared to the moderate VACS trajectory. 


\begin{abstract}
A sensitivity analysis excluding prescribed opioid receipt based on pharmacy fill/refill data (Supplemental Table 2) as a covariate did not change the primary findings.
\end{abstract}

\title{
Opioid use trajectory and mortality
}

Kaplan-Meier curves (Figure 2) showed that participants within the high, then deescalating opioid trajectory had significantly higher mortality throughout follow-up: only half of individuals in this group survived beyond the eight years following the baseline survey. Individuals within the escalating opioid use trajectory were also less likely to survive at all time points compared to individuals with no lifetime or stable, infrequent use of opioids. In Cox regression, predictors of mortality included older age, white race/ethnicity, lower education level, any housing instability, any history of cancer, reported pain interference, lack of viral suppression, being a current smoker, and having HCV (Table 3). Long-term and high-dose prescribed opioid receipt predicted mortality (adjusted hazard ratio [AHR], 95\% CI: 1.25 [1.051.50]). Compared to those with stable, infrequent use, escalating use and de-escalating use had higher risk of death (unadjusted hazard ratios [UHR], 95\% Cl: 1.27 [1.13-1.43]) and 1.76 [1.542.02]), respectively, in unadjusted analyses. In the multivariable model, these differences did not remain significant ( $p$-value $=0 \cdot 25)$. In a sensitivity analysis excluding prescribed opioid receipt as a covariate (tables presented in Supplemental Tables 2 and 3), findings were similar for opioid trajectories.

\section{DISCUSSION}

In a well-characterized sample of patients engaged in care, these analyses provide a more comprehensive understanding of how trajectories of self-reported opioid use impact overall disease severity for PWH. Individuals with HIV who report high frequency opioid use 
have increased mortality risk over time, even when frequency of opioid use de-escalates. In adjusted Cox regression analyses, differences in mortality by opioid trajectory group did not remain significant, although the direction of effects were similar.

Individuals within the high, then de-escalating opioid use trajectory had higher overall disease severity and significant mortality over follow-up compared to the other patterns of selfreported opioid use. One in three patients with high, then de-escalating opioid use and one in ten patients with escalating opioid use were classified within the extremely high VACS score trajectory (i.e., higher mortality risk), compared to only one in fifteen patients with no lifetime opioid use. The decrease in opioid use seen within the de-escalating trajectory may be due to several factors including death (and therefore, attrition) of the highest frequency users as well as the "sick quitter" phenomenon, in which individuals with more serious medical issues are less likely to continue a high frequency of substance use (25), which could include use of opioids. Decreased use may also be related to the Opioid Safety Initiative (OSI), launched in 2013 by VA, to decrease opioid prescribing practices associated with adverse outcomes (26). The OSI has been shown to decrease the use of high-dosage opioids and benzodiazepines in veterans (26). De-escalating use may also be due to forced tapering of prescribed doses. Previous work has highlighted risks associated with forced tapering of prescribed opioids, including termination of care and heroin initiation; however, evaluating the impact of forced tapering was beyond the scope of this particular analysis $(27,28)$. Individuals in this group began with a higher frequency of opioid use compared to any of the other trajectories, with apparent long-lasting impact. This finding highlights the importance of eliciting a comprehensive history of previous opioid use (including frequency of use) within clinical encounters and reinforces recommendations for judicious use of prescribed opioids for the treatment of pain, screening and identification of opioid use, and provision of medications for opioid use disorder for PWH (29-32). In addition, this finding suggests that an overall measure of disease severity, rather than a single clinical 
marker such as CD4 count or viral load (12), may be needed to evaluate the association of opioids on and long-term physiologic effects and overall health among $\mathrm{PWH}$.

Even after accounting for clinical factors, prescribed medications, and selected comorbidities, socioeconomic determinants of health including race/ethnicity, annual income, and education level remained significant determinants of both VACS score trajectory membership and mortality. Despite significant progress in improving survival for persons with HIV, these factors continue to impact HIV disease progression. Our findings emphasize the need to characterize and address the upstream drivers that result in these disparities which, unfortunately, continue to heavily influence disease severity and mortality. Our analyses yielded surprising results regarding the impact of race/ethnicity. While non-white participants were more likely to be grouped within the high or extremely high VACS trajectories (i.e., higher risk of mortality), they had a lower hazard of mortality within the survival analyses. This seemingly contradictory result could result from the averaging of a changing hazard over time into a single value (33), the selected covariates adjusted for within the final model, as well as a greater likelihood of suicide, violence-related, or accidental death among white patients. Cause of death data reports that nearly $8 \%$ of total deaths were due to unnatural causes (see Supplemental Table 4) and unnatural death was listed more often for white patients (10\% compared to $7 \%$ for non-white); however, additional analyses in larger samples to explore this in depth is warranted. Future analyses focused on examining causes of death associated with long-term patterns of opioid use may yield important insights into the long-term physiologic effects of opioids.

Another important correlate of VACS trajectory membership and mortality was reported pain interference. Unlike many previous observational studies, we were able to include a measure of pain interference rather than pain intensity. Pain intensity is reported within electronic health records which results in its frequent use within studies; however, it may be a less sensitive measure of the impact of chronic pain on physical and emotional functioning. 
Evidence suggests that heightened pain intensity and pain interference with daily activities and receipt of opioid therapy is associated with increased risk of adverse clinical outcomes, including opioid-related overdose and suicide, potentially because of pain's effects on neural systems of reward thus contributing to riskier behavior $(34,35)$. The association of pain with opioid overdose is likely mediated by the quantity of opioids prescribed. Previous work with the VACS cohort demonstrated an association between greater pain interference and increased extra-medical use of opioids (7). Despite a high frequency of opioid use, individuals within the escalating and de-escalating opioid trajectories reported greater pain interference within their daily life. This suggests the need for pain management strategies beyond opioids to prevent the increased mortality risk associated with high levels of opioid use. Taken together, these findings suggest that heightened pain interference is an important contributor to initiation of opioid therapy and escalating dose and the pathway to misuse, use of illicit opioids and risk of overdose.

Previously published studies using the VACS cohort have reported a shift from prescription opioid use to heroin use over time. Specifically, Banerjee et al. found that newonset non-medical use of prescription opioids strongly predicted heroin initiation (36). This shift was not apparent within our data (see Supplemental Figure 2). While there was significant overlap in our study populations, we did not exclude individuals with a prior history of nonmedical prescription opioid or heroin use. In addition, heroin use remained relatively rare throughout the study period and trajectories largely captured the use of opioids. Of note, our analysis did not include the provision of opioid agonist therapies (OAT, i.e., methadone or buprenorphine) for treatment of opioid use disorder. Prior work with VACS data demonstrated that OAT's impact on VACS Index scores varied by self-reported opioid use and viral suppression (17). The authors concluded that at a maximum, receipt of OAT could change 
VACS score by approximately 4 points and that this change is likely limited to PWH with detectable HIV-RNA who currently use opioids (17).

This study is subject to several limitations. First, the joint-trajectory modeling did not allow for us to evaluate if changes in the self-reported opioid use trajectory would lead to changes in VACS Index trajectory. Second, our pharmacy data captures medications filled in the outpatient setting within the Veterans Health Administrative system and thus does not capture over-the-counter medications and medications, including opioids, provided in the hospital or outside the VA. Covariates related to substance use and the question used to create the opioid trajectories relied on self-report; therefore, these may be subject to recall and social desirability bias, which may mask stronger true associations and attenuate our results towards the null. Third, our sample consisted of mostly older African American men with HIV engaged in regular care and may not be generalizable to all people with HIV. Despite these limitations, our approach had the advantage of using all available data from each participant, even participants with missing data for some of the survey waves and accounting for non-random missing data due to death. An additional strength was inclusion of pharmacy data in combination with selfreported data which allowed us to evaluate the impact of prescribed opioids and other psychoactive medications including benzodiazepines and gabapentinoids, which may reinforce or diminish opioid effects and mortality risk.

In summary, PWH who reported high frequency opioid use had increased mortality risk over time, even when frequency of opioid use de-escalates. Efforts to continue to identify and reduce opioid exposure among $\mathrm{PWH}$ are urgently needed. 


\section{References}

1. Degenhardt L, Grebely J, Stone J, Hickman M, Vickerman P, Marshall BDL, et al. Global patterns of opioid use and dependence: harms to populations, interventions, and future action. Lancet. 2019;394(10208):1560-79.

2. Control CfD, Prevention, Statistics NCfH. Compressed Mortality File 1999-2016 on CDC WONDER Online Database. 2017. Data are from the Compressed Mortality File. 1999;2016.

3. Stock Jonathan D, Chui P, Rosman L, Malm Brian J, Bastian L, Burg Matthew M. Abstract 12773: Association of Opioid Use With Atrial Fibrillation in a Post-9/11 Veteran Population. Circulation. 2018;138(Suppl_1):A12773-A.

4. Ronan MV, Herzig SJ. Hospitalizations Related To Opioid Abuse/Dependence And Associated Serious Infections Increased Sharply, 2002-12. Health Affairs. 2016;35(5):832-7. 5. Clausen T, Waal H, Thoresen M, Gossop M. Mortality among opiate users: opioid maintenance therapy, age and causes of death. Addiction. 2009;104(8):1356-62.

6. Gressler LE, Martin BC, Hudson TJ, Painter JT. Relationship between concomitant benzodiazepine-opioid use and adverse outcomes among US veterans. Pain. 2018;159(3):4519.

7. Barry DT, Goulet JL, Kerns RK, Becker WC, Gordon AJ, Justice AC, et al. Nonmedical use of prescription opioids and pain in veterans with and without HIV. Pain. 2011;152(5):1133-8. 8. Roy S, Ninkovic J, Banerjee S, Charboneau RG, Das S, Dutta R, et al. Opioid Drug Abuse and Modulation of Immune Function: Consequences in the Susceptibility to Opportunistic Infections. Journal of Neuroimmune Pharmacology. 2011;6(4):442.

9. Edelman EJ, Gordon KS, Crothers K, Akgun K, Bryant KJ, Becker WC, et al. Association of Prescribed Opioids With Increased Risk of Community-Acquired Pneumonia Among Patients With and Without HIV. JAMA Intern Med. 2019;179(3):297-304.

10. McCance-Katz EF, Sullivan LE, Nallani S. Drug Interactions of Clinical Importance among the Opioids, Methadone and Buprenorphine, and Other Frequently Prescribed Medications: A Review. The American Journal on Addictions. 2010;19(1):4-16.

11. Lemons A, DeGroote N, Peréz A, Craw J, Nyaku M, Broz D, et al. Opioid Misuse Among HIV-Positive Adults in Medical Care: Results From the Medical Monitoring Project, 2009-2014.

JAIDS Journal of Acquired Immune Deficiency Syndromes. 2019;80(2):127-34.

12. Edelman E, Gordon K, Tate J, Becker W, Bryant K, Crothers K, et al. The impact of prescribed opioids on CD4 cell count recovery among HIV-infected patients newly initiating antiretroviral therapy. HIV Medicine. 2016;17(10):728-39.

13. Tate JP, Justice AC, Hughes MD, Bonnet F, Reiss P, Mocroft A, et al. An internationally generalizable risk index for mortality after one year of antiretroviral therapy. AIDS. 2013;27(4):563-72.

14. Akgün KM, Gordon K, Pisani M, Fried T, McGinnis KA, Tate JP, et al. Risk factors for hospitalization and medical intensive care unit (MICU) admission among HIV-infected Veterans. Journal of acquired immune deficiency syndromes (1999). 2013;62(1):52-9.

15. Salinas JL, Rentsch C, Marconi VC, Tate J, Budoff M, Butt AA, et al. Baseline, TimeUpdated, and Cumulative HIV Care Metrics for Predicting Acute Myocardial Infarction and AllCause Mortality. Clinical Infectious Diseases. 2016;63(11):1423-30.

16. Marshall BDL, Tate JP, McGinnis KA, Bryant KJ, Cook RL, Edelman EJ, et al. Long-term alcohol use patterns and HIV disease severity. AIDS (London, England). 2017;31(9):1313-21. 17. McGinnis KA, Fiellin DA, Skanderson M, Hser YI, Lucas GM, Justice AC, et al. Opioid use trajectory groups and changes in a physical health biomarker among HIV-positive and uninfected patients receiving opioid agonist treatment. Drug Alcohol Depend. 2019;204:107511. 18. Justice AC, Dombrowski E, Conigliaro J, Fultz SL, Gibson D, Madenwald T, et al. Veterans aging cohort study (VACS): overview and description. Medical care. 2006;44(8 Suppl 2):S13. 
19. Edelman EJ, Li Y, Barry D, Braden JB, Crystal S, Kerns RD, et al. Trajectories of selfreported opioid use among patients with HIV engaged in care: Results from a national cohort study. JAIDS Journal of Acquired Immune Deficiency Syndromes. 2020;Publish Ahead of Print. 20. Tate JP, Sterne JAC, Justice AC, Study ftVAC, Collaboration tATC. Albumin, white blood cell count, and body mass index improve discrimination of mortality in HIV-positive individuals. AIDS. 2019;33(5):903-12.

21. Sohn M-W, Arnold N, Maynard C, Hynes DM. Accuracy and completeness of mortality data in the Department of Veterans Affairs. Population Health Metrics. 2006;4(1):2.

22. Gomes T, Greaves S, van den Brink W, Antoniou T, Mamdani MM, Paterson JM, et al. Pregabalin and the Risk for Opioid-Related Death: A Nested Case-Control Study. Annals of Internal Medicine. 2018;169(10):732-4.

23. Jones BL, Nagin DS. Advances in Group-Based Trajectory Modeling and an SAS Procedure for Estimating Them. Sociological Methods \& Research. 2007;35(4):542-71.

24. Haviland AM, Jones BL, Nagin DS. Group-based Trajectory Modeling Extended to Account for Nonrandom Participant Attrition. Sociological Methods \& Research. 2011;40(2):36790.

25. Freiberg MS, McGinnis KA, Kraemer K, Samet JH, Conigliaro J, Curtis Ellison R, et al. The association between alcohol consumption and prevalent cardiovascular diseases among HIV-infected and HIV-uninfected men. Journal of acquired immune deficiency syndromes (1999). 2010;53(2):247-53.

26. Lin LA, Bohnert ASB, Kerns RD, Clay MA, Ganoczy D, Ilgen MA. Impact of the Opioid Safety Initiative on opioid-related prescribing in veterans. Pain. 2017;158(5):833-9.

27. Binswanger IA, Glanz JM, Faul M, Shoup JA, Quintana LM, Lyden J, et al. The Association between Opioid Discontinuation and Heroin Use: A Nested Case-Control Study. Drug and Alcohol Dependence. 2020;217:108248.

28. Perez HR, Buonora M, Cunningham CO, Heo M, Starrels JL. Opioid Taper Is Associated with Subsequent Termination of Care: a Retrospective Cohort Study. J Gen Intern Med. 2020;35(1):36-42.

29. Bruce RD, Merlin J, Lum PJ, Ahmed E, Alexander C, Corbett AH, et al. 2017 HIVMA of IDSA Clinical Practice Guideline for the Management of Chronic Pain in Patients Living With HIV. Clinical Infectious Diseases. 2017;65(10):e1-e37.

30. US Preventive Services Task Force. Draft recommendation statement: Illicit drug use, including nonmedical use of prescription drugs: screening. 2019.

31. Substance Abuse and Mental Health Services Administration. Medications for Opioid Use Disorder. Treatment Improvement Protocol (TIP) Series 63, Full Document. HHS Publication No. (SMA) 18-5063FULLDOC. Rockville, MD: Substance Abuse and Mental Health Services Administration; 2018.

32. Oldfield BJ, Munoz N, McGovern MP, Funaro M, Villanueva M, Tetrault JM, et al. Integration of care for HIV and opioid use disorder: a systematic review of interventions in clinical and community-based settings. AIDS. 2018.

33. Hernan MA. The hazards of hazard ratios. Epidemiology (Cambridge, Mass). 2010;21(1):13-5.

34. Bohnert ASB, Ilgen MA. Understanding Links among Opioid Use, Overdose, and Suicide. New England Journal of Medicine. 2019;380(1):71-9.

35. Elman I, Borsook D, Volkow ND. Pain and suicidality: insights from reward and addiction neuroscience. Progress in neurobiology. 2013;109:1-27.

36. Banerjee G, Edelman EJ, Barry DT, Becker WC, Cerdá M, Crystal S, et al. Non-medical use of prescription opioids is associated with heroin initiation among US veterans: a prospective cohort study. Addiction. 2016;111(11):2021-31. 


\section{Acknowledgements}

We would like to acknowledge the veterans who participate in the Veterans Aging Cohort Study (VACS) and the study coordinators and staff at each VACS site and at the West Haven

Coordinating Center. We would also like to thank Dr. Bobby Jones for his assistance with the joint-trajectory modeling procedures. The authors declare that they have no conflict of interest. This work was supported by supported by the National Institute on Drug Abuse (5R01DA040471-03), National Institute on Alcohol Abuse and Alcoholism (U10-AA13566), National Institute of Mental Health (F31-MH114736-01A1), and National Institute of Allergy and Infectious Diseases (T32-AI052074). 
Figure 1. Relationship between membership in group trajectories by frequency of self-reported opioid use and VACS index 2.0 score. Association between membership in VACS index 2.0 score trajectory and self-reported opioid use trajectory was statistically significant $(<0.0001)$.

Figure 2. Kaplan-Meier survival curves overall and by opioid use trajectory group membership over study period (2002-2018) for people with HIV. Panels show Kaplan-Meier curves with total number at risk at each time point for each opioid trajectory. ${ }^{a}$ 


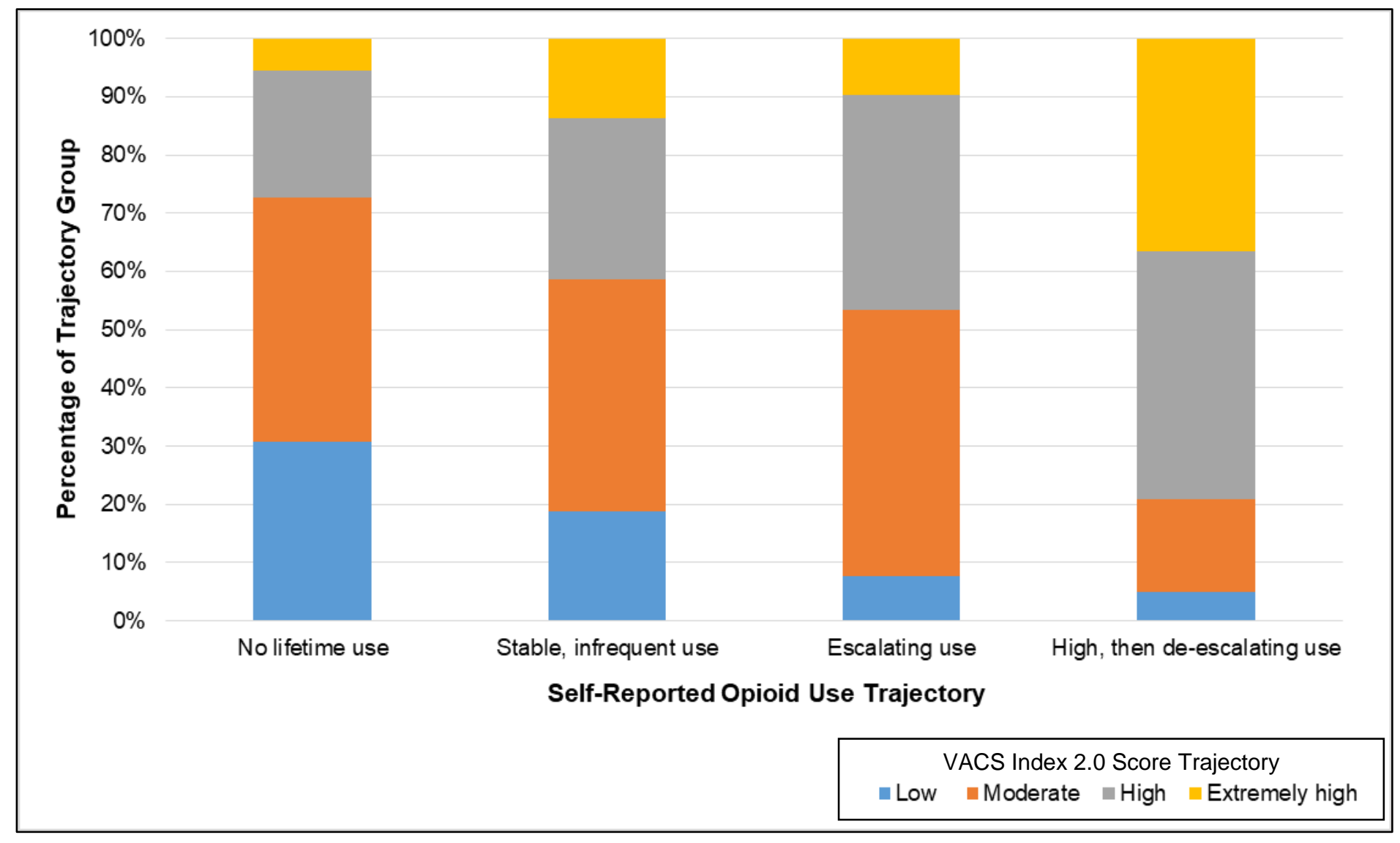




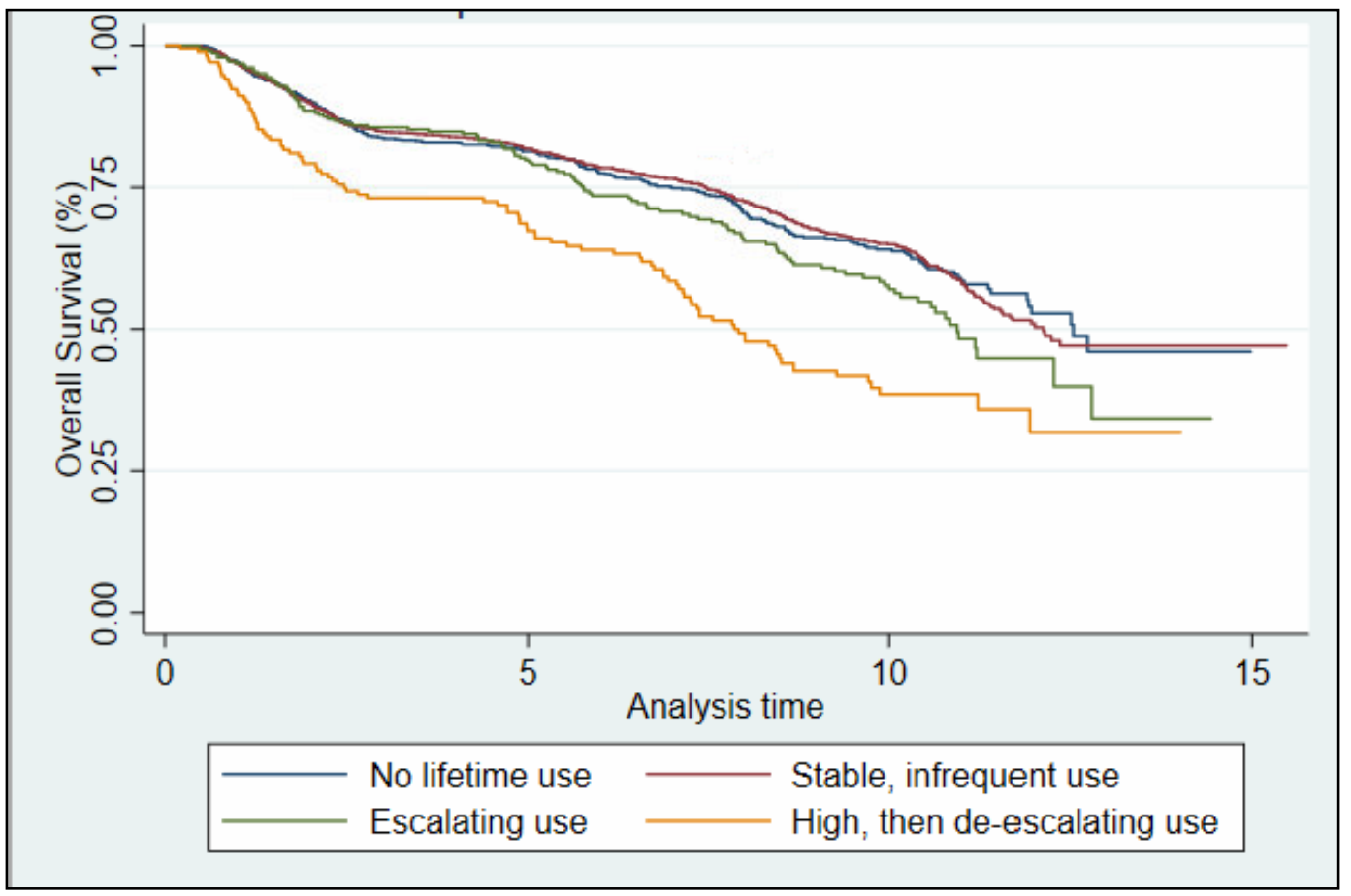

\section{No lifetime use}

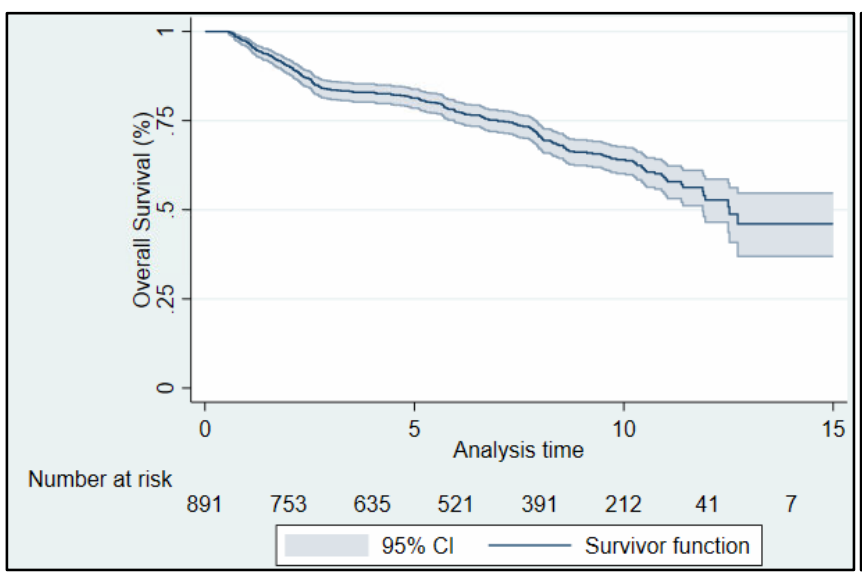

\section{Escalated use}

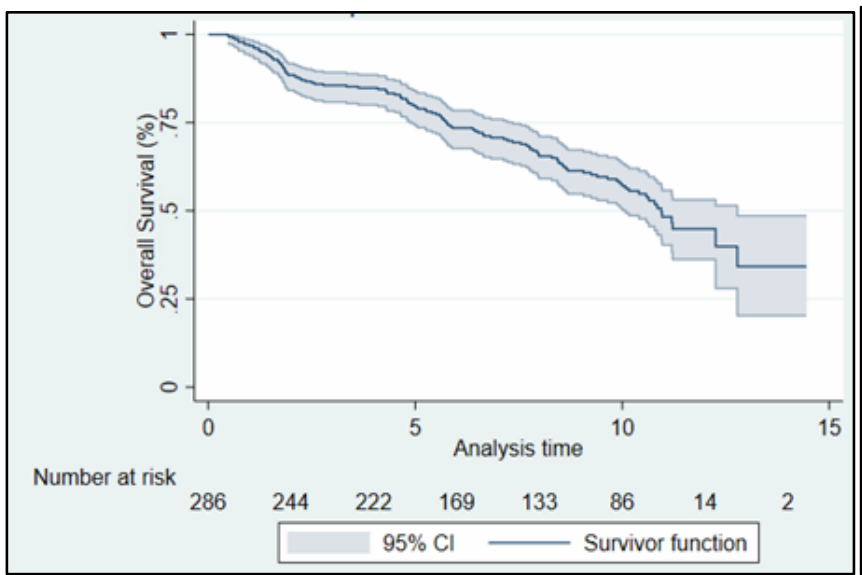

High, then de-escalating use

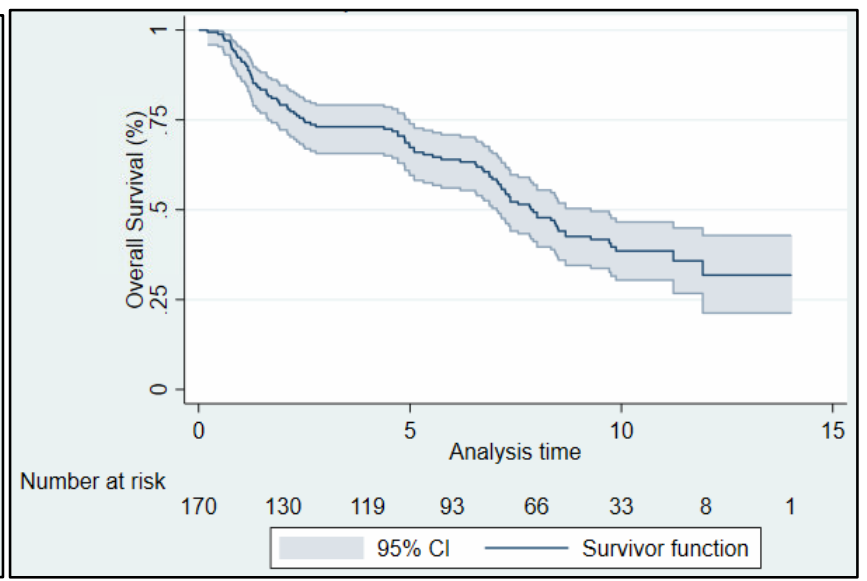

Stable, infrequent use

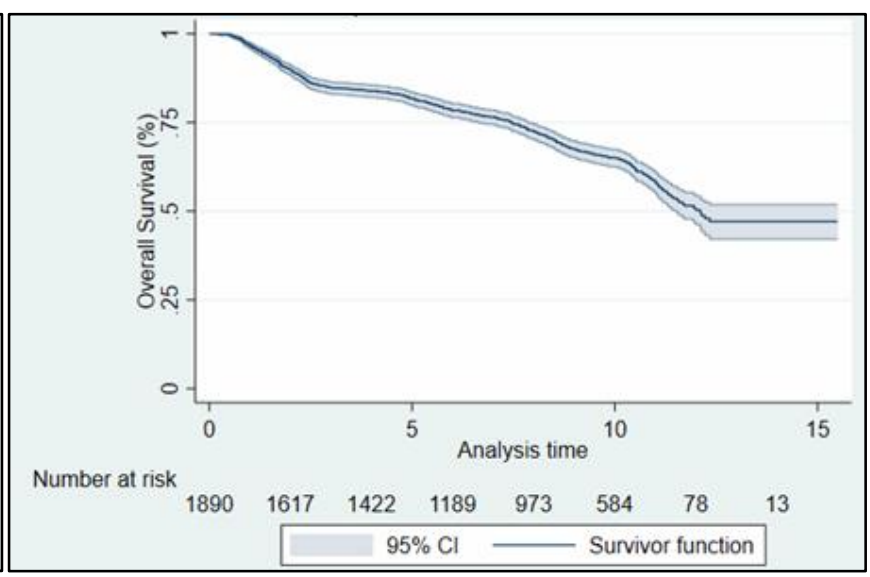

a Log-rank test resulted in $p$-value $<0.001$. 
Table 1. Participant characteristics, HIV and clinical factors, prescribed medications, substance use, and self-reported opioid use frequency at baseline by Veterans Aging Cohort Study Index 2.0 score trajectory group ( $n$, \% except as noted).

VACS Index 2.0 trajectory group

\begin{tabular}{|c|c|c|c|c|c|c|}
\hline Participant characteristics & $\begin{array}{c}\text { Overall } \\
(N=\mathbf{3}, \mathbf{6 5 8})\end{array}$ & $\begin{array}{c}\text { Low } \\
(N=\mathbf{7 3 8 , 2 0 . 2 \% )})\end{array}$ & $\begin{array}{c}\text { Moderate } \\
(N=1,446,39.5 \%) \\
\end{array}$ & $\begin{array}{c}\text { High } \\
(N=1012,27.7 \%)\end{array}$ & $\begin{array}{c}\text { Extreme } \\
(N=\mathbf{4 6 2}, 12.6 \%)\end{array}$ & $P$ value \\
\hline Age at first interview, median (IQR) & $49.7(44.1,55.1)$ & $44.0(37.5,50.4)$ & $49.5(44.3,54.8)$ & $51.7(47.0,56.9)$ & $52.8(48.3,58.2)$ & $<0.0001$ \\
\hline Sex at birth & & & & & & 0.15 \\
\hline Female & $97(2.7)$ & $23(3.1)$ & $44(3.0)$ & $17(1.7)$ & $13(2.8)$ & \\
\hline Male & $3561(97.4)$ & 715 (96.7) & $1402(97.0)$ & $995(98.3)$ & $449(97.2)$ & \\
\hline Race/ethnicity & & & & & & $<0.0001$ \\
\hline White & 709 (19.4) & $178(24.1)$ & 309 (21.4) & $173(17.1)$ & $49(10.6)$ & \\
\hline Black & $2444(66.8)$ & $440(59.6)$ & $934(64.6)$ & $710(70.2)$ & $360(77.9)$ & \\
\hline Hispanic & $353(9.7)$ & $84(11.4)$ & $142(9.8)$ & $87(8.6)$ & $40(8.7)$ & \\
\hline Other & $152(4.2)$ & $36(4.9)$ & $61(4.2)$ & $42(4.2)$ & $13(2.8)$ & \\
\hline Education level & & & & & & $<0.0001$ \\
\hline High school or less & $1458(40.3)$ & $207(28.3)$ & $575(40.0)$ & 452 (44.9) & $224(50.0)$ & \\
\hline Some college or more & $2164(59.8)$ & 525 (71.7) & $861(60.0)$ & $554(55.1)$ & $224(50.0)$ & \\
\hline Marital Status & & & & & & $<0.0001$ \\
\hline Never married & $825(22.9)$ & $185(25.4)$ & $353(24.7)$ & $203(20.4)$ & $84(18.6)$ & \\
\hline Married/living with partner & $1481(41.1)$ & $234(32.1)$ & $544(38.1)$ & $464(46.6)$ & $239(53.0)$ & \\
\hline Divorced/widowed & $1299(36.0)$ & $310(42.5)$ & $532(37.2)$ & $329(33.0)$ & $128(28.4)$ & \\
\hline Housing instability ever ${ }^{a}$ & $1539(42.3)$ & $253(34.5)$ & $612(42.5)$ & $453(44.9)$ & $221(48.2)$ & $<0.0001$ \\
\hline Location of residence & & & & & & 0.0410 \\
\hline Urban & $3447(95.1)$ & $689(93.7)$ & $1353(94.6)$ & $963(95.6)$ & $442(97.6)$ & \\
\hline Suburban & $102(2.8)$ & $22(3.0)$ & $48(3.4)$ & $25(2.5)$ & 7 (1.6) & \\
\hline Rural & $77(2.1)$ & $24(3.3)$ & $30(2.1)$ & $19(1.9)$ & $4(0.9)$ & \\
\hline Annual income & & & & & & $<0.0001$ \\
\hline$<\$ 11,999$ & $1793(50.6)$ & $237(33.2)$ & $685(49.0)$ & $571(57.7)$ & $300(68.0)$ & \\
\hline$\$ 12,000-\$ 49,999$ & $1485(41.9)$ & $366(51.2)$ & $615(44.0)$ & $379(38.3)$ & $125(28.3)$ & \\
\hline$\geq \$ 50,000$ & $264(7.5)$ & $112(15.7)$ & $97(6.9)$ & $39(3.9)$ & $16(3.6)$ & \\
\hline $\begin{array}{l}\text { Average number of completed } \\
\text { surveys, mean (SD) }\end{array}$ & $4.6(2.2)$ & $4.9(2.2)$ & $5.0(2.2)$ & $4.6(2.2)$ & $3.3(2.1)$ & $<0.0001$ \\
\hline Died during follow-up & $1397(38.2)$ & $70(9.5)$ & 389 (26.9) & $533(52.7)$ & $405(87.7)$ & $<0.0001$ \\
\hline Loss to follow-up & $864(23.6)$ & $259(30.0)$ & $415(48.0)$ & $170(19.7)$ & $20(2.3)$ & $<0.0001$ \\
\hline $\begin{array}{l}\text { HIV and clinical factors } \\
\text { Antiretroviral therapy receipt }\end{array}$ & $2836(77.5)$ & $588(79.7)$ & $1106(76.5)$ & $784(77.5)$ & $358(77.5)$ & 0.4146 \\
\hline
\end{tabular}




\begin{tabular}{|c|c|c|c|c|c|c|}
\hline 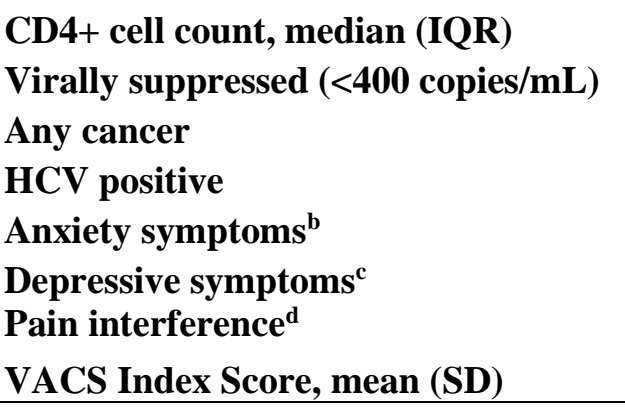 & $\begin{array}{l}379(229,564) \\
1769(48.6) \\
698(19.1) \\
1395(38.1) \\
1331(37.4) \\
820(22.6) \\
1227(33.8) \\
58.7(16.9) \\
\end{array}$ & $\begin{array}{c}554.5(410,748) \\
472(64.5) \\
75(10.2) \\
56(7.6) \\
268(36.9) \\
145(19.8) \\
181(24.7) \\
39.3(7.9) \\
\end{array}$ & $\begin{array}{l}406(263,570.5) \\
707(49.2) \\
276(19.1) \\
462(32.0) \\
538(38.3) \\
314(21.8) \\
467(32.6) \\
53.8(7.7) \\
\end{array}$ & $\begin{array}{l}299(174,465) \\
423(42.0) \\
249(24.6) \\
538(53.2) \\
365(37.2) \\
235(23.4) \\
385(38.2) \\
67.0(8.9) \\
\end{array}$ & $\begin{array}{l}213(98,330) \\
167(36.2) \\
98(21.2) \\
339(73.4) \\
160(36.0) \\
126(27.9) \\
194(42.7) \\
86.9(13.1) \\
\end{array}$ & $\begin{array}{c}<0.0001 \\
<0.0001 \\
<0.0001 \\
<0.0001 \\
0.8213 \\
0.0090 \\
<0.0001 \\
<0.0001\end{array}$ \\
\hline $\begin{array}{l}\text { Prescribed medications } \\
\text { Benzodiazepine, current prescription } \\
\text { None } \\
\text { Short-term, }<90 \text { days } \\
\text { Long-term, }>=90 \text { days } \\
\text { Antidepressant, current prescription } \\
\text { None } \\
\text { Short-term, }<90 \text { days } \\
\text { Long-term, >=90 days } \\
\text { Gabapentinoid, current prescription } \\
\text { None } \\
\text { Short-term, }<90 \text { days } \\
\text { Long-term, }>=90 \text { days } \\
\text { Opioid, current prescription } \\
\text { None } \\
\text { Short-term, }<90 \text { days } \\
\text { Long-term, }>=90 \text { days }\end{array}$ & $\begin{array}{c}3154(86.2) \\
215(5.9) \\
289(7.9) \\
2300(62.9) \\
480(13.1) \\
878(24.0) \\
3270(89.4) \\
160(4.4) \\
228(6.2) \\
2644(72.3) \\
731(20.0) \\
283(7.7) \\
\end{array}$ & $\begin{array}{c}648(87.8) \\
35(4.7) \\
55(7.5) \\
517(70.1) \\
64(8.7) \\
157(21.3) \\
681(92.3) \\
22(3.0) \\
35(4.7) \\
571(77.4) \\
132(17.9) \\
35(4.7) \\
\end{array}$ & $\begin{array}{c}1260(87.1) \\
76(5.3) \\
110(7.6) \\
892(61.7) \\
186(12.9) \\
368(25.5) \\
1303(90.1) \\
58(4.0) \\
85(5.9) \\
1077(74.5) \\
270(18.7) \\
99(6.9) \\
\end{array}$ & $\begin{array}{c}849(83.9) \\
65(6.4) \\
98(9.7) \\
611(60.4) \\
151(14.9) \\
250(24.7) \\
885(87.5) \\
51(5.0) \\
76(7.5) \\
686(67.8) \\
226(22.3) \\
100(9.9) \\
\end{array}$ & $\begin{array}{c}397(85.9) \\
39(8.4) \\
26(5.6) \\
280(60.6) \\
79(17.1) \\
103(22.3) \\
401(86.8) \\
29(6.3) \\
32(6.9) \\
\\
310(67.1) \\
103(22.3) \\
49(10.6) \\
\end{array}$ & 0.0136 \\
\hline $\begin{array}{l}\text { Substance use } \\
\text { Current smoker } \\
\text { Unhealthy alcohol use }^{\mathrm{e}} \\
\text { Cannabis }^{\mathrm{f}} \\
\text { Stimulant use }^{\mathrm{f}} \\
\text { Self-reported opioid use trajectory } \\
\text { group } \\
\text { No lifetime use } \\
\text { Stable, infrequent use } \\
\text { Escalating use } \\
\text { De-escalating use }\end{array}$ & $\begin{array}{c}2805(76.7) \\
1331(36.4) \\
1008(27.6) \\
161(4.4) \\
916(25.0) \\
2250(61.5) \\
290(7.9) \\
202(5.5) \\
\end{array}$ & $\begin{array}{c}450(61.0) \\
250(33.9) \\
195(26.4) \\
30(4.1) \\
282(38.2) \\
424(57.5) \\
22(3.0) \\
10(1.4)\end{array}$ & $\begin{array}{c}384(26.6) \\
897(62.0) \\
133(9.2) \\
32(2.2)\end{array}$ & $\begin{array}{c}199(19.7) \\
620(61.3) \\
107(10.6) \\
86(8.5)\end{array}$ & $\begin{array}{c} \\
51(11.0) \\
309(66.9) \\
28(6.1) \\
74(16.0)\end{array}$ & $\begin{array}{c}<\mathbf{0 . 0 0 0 1} \\
0.1502 \\
0.5478 \\
0.2830 \\
\\
<\mathbf{0 . 0 0 0 1}\end{array}$ \\
\hline
\end{tabular}




\section{Notes:}

Bolding indicates a p-value $<0.05$.

a reported "yes" to "Have you ever been without a permanent address that you call home?"

b anxiety symptoms considered present if response included any of the following: "bothers me a little", "it bothers me", "it bothers me a lot"

c depressive symptoms, defined as present on PHQ-9 score $>9$

d self-reported pain interference in daily live, defined as present if response included any of the following: "moderately", "quite a bit", or "extremely"

${ }^{\mathrm{e}}$ Alcohol Use Disorders Identification Test Consumptions (AUDIT-C)- defined as $\geq 3$ for women, $\geq 4$ for men

${ }^{\mathrm{f}}$ any use endorsed in past 12 months 
Table 2. Factors associated with membership in Veterans Aging Cohort Study Index 2.0 score trajectories in the final multinomial logistic regression model.

VACS Index 2.0 trajectory group, adjusted odds ratio (95\% confidence interval)

\begin{tabular}{|c|c|c|c|c|c|}
\hline Sociodemographic characteristics & $\begin{array}{c}\text { Low } \\
(N=738,20.2 \%)\end{array}$ & $\begin{array}{c}\text { Moderate } \\
(N=1,446,39.5 \%)\end{array}$ & $\begin{array}{c}\text { High } \\
(N=1012,27.7 \%)\end{array}$ & $\begin{array}{c}\text { Extreme } \\
(N=462,12.6 \%)\end{array}$ & $P$ value \\
\hline Race/ethnicity (ref: White) & & & & & 0.0005 \\
\hline Black & $0.88(0.69,1.12)$ & REF & $1.30(1.03,1.65)$ & $1.91(1.32,2.77)$ & \\
\hline Hispanic & $1.14(0.80,1.63)$ & REF & $1.06(0.75,1.51)$ & $1.15(0.67,1.97)$ & \\
\hline Other & $0.96(0.59,1.57)$ & REF & $1.21(0.76,1.93)$ & $0.87(0.39,1.94)$ & \\
\hline Education level (ref: high school or less) & $1.42(1.15,1.75)$ & REF & $0.90(0.75,1.07)$ & $0.84(0.66,1.08)$ & 0.0003 \\
\hline Marital Status (ref: married) & & & & & $<0.0001$ \\
\hline Never married & $0.96(0.74,1.24)$ & REF & $0.74(0.59,0.93)$ & $0.66(0.48,0.90)$ & \\
\hline Divorced/widowed & $1.21(0.97,1.51)$ & REF & $0.76(0.62,0.92)$ & $0.60(0.46,0.79)$ & \\
\hline Housing instability ever & $1.04(0.84,1.29)$ & REF & $0.88(0.73,1.07)$ & $0.92(0.71,1.18)$ & 0.4712 \\
\hline Location of residence & & & & & 0.3388 \\
\hline Suburban & $1.01(0.59,1.73)$ & REF & $0.74(0.44,1.25)$ & $0.55(0.23,1.29)$ & \\
\hline Rural & $1.61(0.88,2.96)$ & REF & $1.05(0.56,1.97)$ & $0.58(0.19,1.80)$ & \\
\hline Annual income (ref: <\$11,999) & & & & & $<0.0001$ \\
\hline$\$ 12,000-\$ 49,999$ & $1.52(1.22,1.88)$ & REF & $0.81(0.67,0.98)$ & $0.60(0.46,0.78)$ & \\
\hline$\geq \$ 50,000$ & $2.49(1.75,3.52)$ & REF & $0.56(0.37,0.85)$ & $0.54(0.30,0.99)$ & \\
\hline Any cancer & $0.47(0.35,0.62)$ & REF & $1.35(1.10,1.67)$ & $1.20(0.90,1.61)$ & $<0.0001$ \\
\hline Depressive symptoms & $1.14(0.88,1.48)$ & REF & $0.92(0.73,1.15)$ & $1.04(0.77,1.41)$ & 0.5078 \\
\hline Pain interference & $0.86(0.68,1.09)$ & REF & $1.19(0.98,1.46)$ & $1.37(1.05,1.78)$ & 0.0109 \\
\hline \\
\hline $\begin{array}{l}\text { Benzodiazepine, current } \\
\text { prescription(ref:none) }\end{array}$ & & & & & 0.1677 \\
\hline Short-term & $1.10(0.71,1.72)$ & REF & $1.14(0.79,1.66)$ & $1.29(0.80,2.09)$ & \\
\hline Long-term & $1.05(0.71,1.55)$ & REF & $1.44(1.04,2.00)$ & $0.77(0.44,1.33)$ & \\
\hline Antidepressant duration (ref: none) & & & & & 0.0719 \\
\hline Short-term & $0.72(0.52,1.00)$ & REF & $1.06(0.81,1.38)$ & $1.11(0.79,1.57)$ & \\
\hline Long-term & $0.81(0.62,1.04)$ & REF & $0.86(0.68,1.07)$ & $0.74(0.54,1.01)$ & \\
\hline Opioid duration and dose (ref: none) & & & & & 0.3317 \\
\hline Short-term + low dose & $1.09(0.84,1.41)$ & REF & $1.24(0.99,1.55)$ & $1.20(0.89,1.63)$ & \\
\hline Short-term + high dose & $1.27(0.52,3.12)$ & REF & $1.39(0.68,2.83)$ & $2.16(0.94,4.94)$ & \\
\hline Long-term + low dose & $1.09(0.65,1.82)$ & REF & $0.90(0.60,1.33)$ & $0.90(0.53,1.53)$ & \\
\hline Long-term + high dose & $1.58(0.68,3.64)$ & REF & $1.98(1.07,3.64)$ & $2.25(1.04,4.88)$ & \\
\hline Substance use & & & & & \\
\hline
\end{tabular}




\begin{tabular}{|l|c|c|c|c|c|}
$\begin{array}{l}\text { Current smoker } \\
\text { Self-reported opioid use trajectory group } \\
\text { (ref: Stable, infrequent use ) }\end{array}$ & $0.59(0.48,0.73)$ & REF & $1.26(1.02,1.57)$ & $1.35(0.98,1.86)$ & $<\mathbf{0 . 0 0 0 1}$ \\
No lifetime use & $1.36(1.01,1.68)$ & REF & $0.77(0.62,0.95)$ & $0.38(0.26,0.54)$ \\
Escalating use & $0.43(0.26,0.71)$ & REF & $1.06(0.78,1.44)$ & $0.51(0.32,0.83)$ \\
High and de-escalating use & $0.89(0.42,1.87)$ & REF & $3.39(2.16,5.33)$ & $5.17(3.19,8.37)$ & $<0.0001$ \\
\hline
\end{tabular}

Notes: Bolding indicates a p-value $<0.05$. Final model chosen using manual backwards selection procedure based on the Akaike Information Critera, starting with all variables significant at $P<0.05$ in Table 1 . Variables within the final model were: race/ethnicity, education level, marital status, housing instability, location of residence, annual income, cancer history, depressive symptoms, pain interference, benzodiazepine prescription, antidepressant duration, opioid duration and dose, smoking history, and self-reported opioid use trajectory. 
Table 3. Adjusted hazard ratios (AHR) for predictors of mortality among participants living with HIV and engaged in care over a 10-year study period using multivariable Cox regression model.

\begin{tabular}{|c|c|c|c|c|}
\hline Sociodemographic characteristics & UHR $(95 \%)$ & p-value & $\operatorname{AHR}(95 \% \mathrm{CI})$ & $P$ value \\
\hline Age (per 10 year) & $1.39(1.33,1.44)$ & \multirow{5}{*}{$\begin{array}{l}<0.0001 \\
<0.0001\end{array}$} & $1.29(1.23,1.35)$ & \multirow{5}{*}{$\begin{array}{l}<0.0001 \\
<0.0001\end{array}$} \\
\hline Race/ethnicity (ref: White) & & & & \\
\hline Black & $0.89(0.81,0.97)$ & & $0.80(0.72,0.88)$ & \\
\hline Hispanic & $0.71(0.61,0.82)$ & & $0.64(0.54,0.75)$ & \\
\hline Other & $0.72(0.59,0.89)$ & & $0.67(0.54,0.84)$ & \\
\hline Education level (ref: high school or less) & $0.75(0.69,0.80)$ & \multirow{4}{*}{$\begin{array}{c}<\mathbf{0 . 0 0 0 1} \\
0.091\end{array}$} & $0.82(0.76,0.89)$ & \multirow{4}{*}{$\begin{array}{c}<\mathbf{0 . 0 0 0 1} \\
0.741\end{array}$} \\
\hline Marital Status (ref: married) & & & & \\
\hline Never married & $0.78(0.71,0.86)$ & & $0.91(0.82,1.01)$ & \\
\hline Divorced/widowed & $0.75(0.69,0.82)$ & & $0.90(0.83,0.99)$ & \\
\hline Housing instability ever & $0.99(0.92,1.06)$ & \multirow{4}{*}{$\begin{array}{c}0.71 \\
<\mathbf{0 . 0 0 0 1}\end{array}$} & $0.86(0.79,0.93)$ & \multirow{4}{*}{$\begin{array}{l}<0.0001 \\
<0.0001\end{array}$} \\
\hline Annual income (ref: <\$11,999) & & & & \\
\hline$\$ 12,000-\$ 49,999$ & $0.72(0.67,0.78)$ & & $0.82(0.75,0.89)$ & \\
\hline$\geq \$ 50,000$ & $0.45(0.38,0.55)$ & & $0.63(0.51,0.77)$ & \\
\hline Any cancer ${ }^{a}$ & $2.08(1.92,2.24)$ & \multirow{2}{*}{$\begin{array}{l}<0.0001 \\
<0.0001\end{array}$} & $1.82(1.68,1.97)$ & \multirow{2}{*}{$\begin{array}{c}<0.0001 \\
0.004\end{array}$} \\
\hline Pain interference $^{\mathrm{a}}$ & $1.32(1.22,1.42)$ & & $1.14(1.05,1.24)$ & \\
\hline HIV and clinical factors & & \multirow{4}{*}{$\begin{array}{l}<0.0001 \\
<0.0001 \\
<0.0001\end{array}$} & & \multirow{4}{*}{$\begin{array}{l}<0.0001 \\
<0.0001 \\
<0.0001 \\
\end{array}$} \\
\hline CD4+ cell count $(\text { per } 100)^{a}$ & $0.89(0.87,0.90)$ & & $0.92(0.91,0.94)$ & \\
\hline Virally suppressed (ref: $>=400 \operatorname{copies} / \mathrm{mL})^{\text {a }}$ & $0.52(0.48,0.56)$ & & $0.52(0.48,0.57)$ & \\
\hline HCV positive ${ }^{a}$ & $1.53(1.42,1.65)$ & & $1.34(1.23,1.46)$ & \\
\hline Prescribed medications & & \multirow{4}{*}{$<0.0001$} & & \multirow{3}{*}{0.127} \\
\hline Antidepressant duration (ref: none) ${ }^{a}$ & & & $1.04(0.91,1.18)$ & \\
\hline Short-term & $1.22(1.09,1.37)$ & & $1.08(0.99,1.18)$ & \\
\hline Long-term & $1.25(1.15,1.35)$ & & & \multirow{3}{*}{0.114} \\
\hline 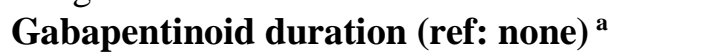 & & \multirow[t]{2}{*}{$<0.0001$} & & \\
\hline Short-term & $1.18(1.00,1.39)$ & & $1.04(0.88,1.24)$ & \\
\hline Long-term & $1.21(1.08,1.36)$ & & $1.10(0.97,1.25)$ & \multirow{3}{*}{0.054} \\
\hline $\begin{array}{l}\text { Benzodiazepine, current } \\
\text { prescription(ref:none) }\end{array}$ & & \multirow{2}{*}{$<0.0001$} & & \\
\hline Short-term & $1.20(1.04,1.40)$ & & $1.08(0.92,1.26)$ & \\
\hline Long-term & $1.28(1.15,1.43)$ & \multirow{6}{*}{$<0.0001$} & $1.12(0.99,1.27)$ & \multirow{6}{*}{0.043} \\
\hline Opioid duration and dose (ref: none) ${ }^{a}$ & & & & \\
\hline Short-term + low dose & $1.11(1.01,1.22)$ & & $1.02(0.92,1.12)$ & \\
\hline Short-term + high dose & $1.17(0.85,1.62)$ & & $1.01(0.72,1.41)$ & \\
\hline Long-term + low dose & $1.34(1.19,1.51)$ & & $1.04(0.91,1.18)$ & \\
\hline Long-term + high dose & $1.80(1.54,2.11)$ & & $1.25(1.05,1.50)$ & \\
\hline Substance use & & \multirow{7}{*}{$\begin{array}{c}<\mathbf{0 . 0 0 0 1} \\
0.640 \\
<\mathbf{0 . 0 0 0 1}\end{array}$} & & \multirow{7}{*}{$\begin{array}{c}<\mathbf{0 . 0 0 0 1} \\
0.435 \\
0.258\end{array}$} \\
\hline Current smoker ${ }^{a}$ & $1.81(1.63,2.00)$ & & $1.50(1.34,1.67)$ & \\
\hline Unhealthy alcohol use $^{a}$ & $0.98(0.90,1.07)$ & & $0.97(0.88,1.06)$ & \\
\hline $\begin{array}{l}\text { Self-reported opioid use trajectory group } \\
\text { (ref: stable, infrequent use) }\end{array}$ & & & & \\
\hline No lifetime use & $0.94(0.86,1.03)$ & & $1.17(1.06,1.29)$ & \\
\hline Escalating use & $1.27(1.13,1.43)$ & & $1.05(0.92,1.20)$ & \\
\hline De-escalating use & $1.76(1.54,2.02)$ & & $1.34(1.16,1.56)$ & \\
\hline
\end{tabular}

Notes: Bolding indicates a p-value $<0.05$. Final multivariable model was selected based on variables significant at $\mathrm{P}$ $<0.05$ in bivariable models or evaluated as meaningful as informed by the literature. Variables within the final model were: age, race/ethnicity, education level, marital status, housing instability, annual income, cancer history, pain interference, $\mathrm{CD} \$+$ cell count, viral suppression, HCV status, gabapentinoid duration, benzodiazepine prescription, antidepressant duration, opioid duration and dose, smoking history, unhealthy alcohol use, and self-reported opioid use trajectory.

a Time-updated variables 
Supplemental Table 1. Description of covariate measures and sources.

\begin{tabular}{|c|c|c|c|}
\hline Covariate name & Type (levels) & Description & Source \\
\hline \multicolumn{4}{|l|}{ Sociodemographic } \\
\hline Sex at birth & Binary (male/female) & Time-invariant & VACS Baseline Survey \\
\hline Race/ethnicity & $\begin{array}{l}\text { Categorical (white, black, Hispanic, } \\
\text { other) }\end{array}$ & Time-invariant & VACS Baseline Survey \\
\hline Education level & $\begin{array}{l}\text { Binary (high school or less/some } \\
\text { college or more) }\end{array}$ & Time-invariant & VACS Baseline Survey \\
\hline Marital Status & $\begin{array}{l}\text { Categorical (never married, } \\
\text { married/living with a partner, } \\
\text { divorced/widowed) }\end{array}$ & Time-invariant & VACS Baseline Survey \\
\hline House instability ever & Binary (yes/no) & Time-varying & $\begin{array}{l}\text { VACS Surveys, defined as present if affirmative } \\
\text { response to question “"'Have you ever been without a } \\
\text { permanent address that you call home?" }\end{array}$ \\
\hline Location of residence & Categorical (urban, suburban, rural) & Time-invariant & $\begin{array}{l}\text { VACS Baseline Survey, based on rural urban } \\
\text { commuting codes }\end{array}$ \\
\hline Annual Income & $\begin{array}{l}\text { Categorical }(<\$ 11,999, \$ 12,000- \\
49,999, \geq \$ 50,000)\end{array}$ & Time-invariant & VACS Baseline Survey \\
\hline $\begin{array}{l}\text { Antiretroviral therapy receipt at } \\
\text { baseline }\end{array}$ & Binary (yes/no) & Time-invariant & $\begin{array}{l}\text { VA Pharmacy Fill/Refill data; defined as present if } \\
\text { receipt of }>3 \text { antiretroviral agents excluding boosters }\end{array}$ \\
\hline CD4+ cell count at baseline & Numerical & Time-invariant & VACS Clinical Data \\
\hline Virally suppressed at baseline & $\begin{array}{l}\text { Binary }(<400 \text { copies } / \mathrm{mL}, \geq 400 \\
\text { copies } / \mathrm{mL})\end{array}$ & Time-invariant & VACS Clinical Data \\
\hline Any cancer & Binary (yes/no) & Time-varying & $\begin{array}{l}\text { National VA Cancer Registry; defined as present if } \\
\text { history of any cancer, excluding non-melanoma skin } \\
\text { cancers }\end{array}$ \\
\hline HCV positive & Binary (yes/no) & Time-varying & VACS Clinical Data \\
\hline Anxiety symptoms & Binary (yes/no) & Time-varying & $\begin{array}{l}\text { VACS Surveys, assessed by the HIV Symptoms Index } \\
\text { Item, anxiety symptoms considered present if response } \\
\text { included any of the following: (anxiety) "bothers me a } \\
\text { little", "it bothers me", "it bothers me a lot" }\end{array}$ \\
\hline Depressive symptoms & Binary (yes/no) & Time-varying & $\begin{array}{l}\text { VACS Surveys, defined as present with Patient Health } \\
\text { Questionnaire-9 (PHQ-9) score }>9\end{array}$ \\
\hline Pain interference & Binary (yes/no) & Time-varying & $\begin{array}{l}\text { VACS Surveys, Question: "During the past } 4 \text { weeks, } \\
\text { how much did pain } \\
\text { interfere with your normal work (including both work } \\
\text { outside the home and housework)?" Response options }\end{array}$ \\
\hline
\end{tabular}




\begin{tabular}{|c|c|c|c|}
\hline & & & $\begin{array}{l}\text { were categorized as no (not at all or a little bit vs. } \\
\text { moderately, quite a bit, or } \\
\text { extremely) }\end{array}$ \\
\hline \multicolumn{4}{|l|}{ Prescribed Medications } \\
\hline $\begin{array}{l}\text { Benzodiazepine, current } \\
\text { prescription }\end{array}$ & $\begin{array}{l}\text { Categorical (none, short-term, long- } \\
\text { term) }\end{array}$ & Time-varying & $\begin{array}{l}\text { VA Pharmacy Fill/Refill data; defined as present if } \\
\text { receipt of any of the following: alprazolam, } \\
\text { chlordiazepoxide, clonazepam, } \\
\text { clorazepate, diazepam, estazolam, eszopiclone, } \\
\text { flurazepam, lorazepam, midazolam, oxazepam, } \\
\text { temazepam, triazolam, zaleplon and zolpidem. } \\
\text { Duration coded as short-term if < }<90 \text { day prescription. }\end{array}$ \\
\hline Antidepressant, current prescription & $\begin{array}{l}\text { Categorical (none, short-term, long- } \\
\text { term) }\end{array}$ & Time-varying & $\begin{array}{l}\text { VA Pharmacy Fill/Refill data; defined as present if } \\
\text { receipt of any of the following: amitriptyline, } \\
\text { amoxapine, bupropion, } \\
\text { citalopram, clomipramine, desipramine, } \\
\text { desvenlafaxine, doxepin, duloxetine, } \\
\text { escitalopram, fluoxetine, fluvoxamine, } \\
\text { imipramine, isocarboxazid, levomilnacipran, } \\
\text { maprotiline, milnacipran, mirtazapine, } \\
\text { nefazodone, nortriptyline, paroxetine, } \\
\text { phenelzine sulfate, protriptyline, selegiline, } \\
\text { sertraline, tranylcypromine, trazodone, } \\
\text { trimipramine, venlafaxine, vilazodone, and } \\
\text { vortioxetine. Duration coded as short-term if }<90 \text { day } \\
\text { prescription. }\end{array}$ \\
\hline Gabapentinoid, current prescription & $\begin{array}{l}\text { Categorical (none, short-term, long- } \\
\text { term) }\end{array}$ & Time-varying & $\begin{array}{l}\text { VA Pharmacy Fill/Refill data; defined as present if } \\
\text { receipt of any of the following: gabapentin, pregabalin. } \\
\text { Duration coded as short-term if < } 90 \text { day prescription. }\end{array}$ \\
\hline Opioid, current prescription & $\begin{array}{l}\text { Categorical (none, short-term and } \\
\text { low dose, short-term and high dose, } \\
\text { long-term and low dose, long-term } \\
\text { and high-dose) }\end{array}$ & Time-varying & $\begin{array}{l}\text { VA Pharmacy Fill/Refill data; defined as present if } \\
\text { receipt of any oral or transdermal opioid in an out- } \\
\text { patient setting. Duration coded as short-term if }<90 \\
\text { day prescription. Dosage coded as low-dose based on a } \\
\text { morphine equivalent daily dose }<50 \mathrm{mg} \text {. }\end{array}$ \\
\hline \multicolumn{4}{|l|}{ Substance Use } \\
\hline Current smoker & Binary (yes/no) & Time-varying & $\begin{array}{l}\text { VACS Surveys, reporting being a current (vs. past) } \\
\text { smoker }\end{array}$ \\
\hline Unhealthy alcohol use & Binary (yes/no) & Time-varying & $\begin{array}{l}\text { VACS Surveys, Alcohol Use Disorders Identification } \\
\text { Test Consumptions (AUDIT-C)- defined as } \geq 3 \text { for } \\
\text { women, } \geq 4 \text { for men }\end{array}$ \\
\hline
\end{tabular}




\begin{tabular}{|l|l|l|l|}
\hline Cannabis & Binary (yes/no) & Time-varying & $\begin{array}{l}\text { VACS Surveys, Question: "How often in the past 12 } \\
\text { months you used each drug... marijuana or hashish". } \\
\text { Answer options: have never tried, no use in the last } \\
\text { year, less than once a month, 1-3 times a month, 1-3 } \\
\text { times a week, 4-6 times a week, every day. Coded as } \\
\text { yes with any use within past 12 months }\end{array}$ \\
\hline Stimulant & Binary (yes/no) & $\begin{array}{l}\text { Time-varying } \\
\text { months you used each drug... stimulants } \\
\text { (amphetamines, uppers, speed, crank, crystal meth, } \\
\text { bam)". Answer options: have never tried, no use in the } \\
\text { last year, less than once a month, 1-3 times a month, 1- } \\
\text { 3 times a week, 4-6 times a week, every day. Coded as } \\
\text { yes with any use within past 12 months }\end{array}$ \\
\hline Self-reported opioid use & Trajectory grouping & $\begin{array}{l}\text { VACS Surveys, Question: "How often in the past 12 } \\
\text { months you used each drug... heroin; prescription } \\
\text { painkillers (such as Oxycontin, Vicodin, Percocet)". } \\
\text { Answer options: have never tried, no use in the last } \\
\text { year, less than once a month, 1-3 times a month, 1-3 } \\
\text { times a week, 4-6 times a week, every day. Frequency } \\
\text { of use utilized within trajectory modeling. NOTE: } \\
\text { Opioid } \\
\text { use was listed as opioids (heroin, morphine, codeine, } \\
\text { opium) in the baseline survey. }\end{array}$ \\
\hline
\end{tabular}


Supplemental Table 2. Factors associated with membership in Veterans Aging Cohort Study index 2.0 score trajectories in the final multinomial logistic regression model excluding prescription opioid use as a covariate.

VACS Index 2.0 trajectory group, adjusted odds ratio (95\% confidence interval)

\begin{tabular}{|c|c|c|c|c|c|}
\hline Sociodemographic characteristics & $\begin{array}{c}\text { Low } \\
(N=738,20.2 \%)\end{array}$ & $\begin{array}{c}\text { Moderate } \\
(N=1,446, \\
39.5 \%)\end{array}$ & $\begin{array}{c}\text { High } \\
(N=1012,27.7 \%)\end{array}$ & $\begin{array}{c}\text { Extreme } \\
(N=462,12.6 \%)\end{array}$ & $P$ value \\
\hline Race/ethnicity (ref: White) & & & & & 0.0005 \\
\hline Black & $0.88(0.69,1.13)$ & REF & $1.30(1.03,1.65)$ & $1.91(1.33,2.77)$ & \\
\hline Hispanic & $1.14(0.80,1.63)$ & REF & $1.06(0.75,1.50)$ & $1.15(0.67,1.97)$ & \\
\hline Other & $0.97(0.59,1.58)$ & REF & $1.22(0.77,1.95)$ & $0.87(0.39,1.94)$ & \\
\hline Education level (ref: high school or less) & $1.42(1.15,1.75)$ & REF & $0.90(0.75,1.07)$ & $0.84(0.66,1.08)$ & 0.0003 \\
\hline Marital Status (ref: married) & & & & & $<0.0001$ \\
\hline Never married & $0.96(0.74,1.24)$ & $\mathrm{REF}$ & $0.74(0.59,0.93)$ & $0.66(0.48,0.91)$ & \\
\hline Divorced/widowed & $1.21(0.97,1.51)$ & REF & $0.76(0.62,0.92)$ & $0.61(0.46,0.80)$ & \\
\hline Housing instability ever & $1.04(0.84,1.29)$ & REF & $0.89(0.74,1.07)$ & $0.91(0.71,1.18)$ & 0.4665 \\
\hline Location of residence & & & & & 0.3422 \\
\hline Suburban & $1.01(0.59,1.73)$ & REF & $0.74(0.44,1.24)$ & $0.55(0.24,1.29)$ & \\
\hline Rural & $1.62(0.88,2.98)$ & REF & $1.05(0.56,1.95)$ & $0.60(0.20,1.85)$ & \\
\hline Annual income (ref: <\$11,999) & & & & & $<0.0001$ \\
\hline$\$ 12,000-\$ 49,999$ & $1.52(1.22,1.88)$ & REF & $0.81(0.67,0.98)$ & $0.60(0.46,0.79)$ & \\
\hline$\geq \$ 50,000$ & $2.49(1.76,3.52)$ & REF & $0.56(0.37,0.85)$ & $0.55(0.30,1.01)$ & \\
\hline Any cancer & $0.47(0.35,0.63)$ & REF & $1.36(1.10,1.68)$ & $1.22(0.91,1.63)$ & $<0.0001$ \\
\hline Depressive symptoms & $1.13(0.87,1.47)$ & REF & $0.91(0.73,1.14)$ & $1.02(0.76,1.38)$ & 0.5032 \\
\hline Pain interference & $0.87(0.69,1.10)$ & REF & $1.21(1.00,1.48)$ & $1.40(1.08,1.82)$ & 0.0062 \\
\hline $\begin{array}{l}\text { Prescribed medications } \\
\text { Benzodiazepine, current } \\
\text { prescription(ref:none) }\end{array}$ & & & & & 0.1230 \\
\hline Short-term & $1.12(0.72,1.74)$ & REF & $1.17(0.81,1.69)$ & $1.32(0.82,2.12)$ & \\
\hline Long-term & $1.08(0.74,1.58)$ & REF & $1.49(1.08,2.05)$ & $0.80(0.47,1.38)$ & \\
\hline
\end{tabular}




\begin{tabular}{|l|c|c|c|c|} 
Antidepressant duration (ref: none) & & & & \\
Short-term & $0.72(0.52,1.01)$ & REF & $1.07(0.82,1.40)$ & $1.13(0.80,1.59)$ \\
Long-term & $0.82(0.63,1.06)$ & REF & $0.88(0.70,1.09)$ & $0.76(0.56,1.04)$ \\
\hline $\begin{array}{l}\text { Substance use } \\
\text { Current smoker }\end{array}$ & $0.59(0.48,0.73)$ & REF & $1.26(1.02,1.56)$ & $1.35(0.98,1.86)$ \\
$\begin{array}{l}\text { Self-reported opioid use trajectory group } \\
\text { (ref: Stable, infrequent use ) }\end{array}$ & & & & $<\mathbf{0 . 0 0 0 1}$ \\
No lifetime use & $1.35(1.09,1.67)$ & REF & $0.76(0.61,0.94)$ & $0.37(0.26,0.53)$ \\
Escalating use & $0.44(0.27,0.73)$ & REF & $1.09(0.81,1.47)$ & $0.53(0.33,0.86)$ \\
De-escalating use & $0.93(0.44,1.92)$ & REF & $3.52(2.26,5.50)$ & $5.39(3.36,8.67)$ \\
\hline
\end{tabular}

Notes: Bolding indicates a p-value $<0.05$. Final model chosen using manual backwards selection procedure based on the Akaike Information Critera, starting with all variables significant at $P<0.05$ in Table 1. 
Supplemental Table 3. Adjusted hazard ratios (AHR) for predictors of mortality among participants living with HIV and engaged in care over a 10-year study period using multivariable Cox regression model excluding prescription opioid use.

\begin{tabular}{|c|c|c|}
\hline Sociodemographic characteristics & $\operatorname{AHR}(95 \% \mathrm{CI})$ & $P$ value \\
\hline Age (per 10 year) & $1.29(1.23,1.35)$ & $<0.0001$ \\
\hline Race/ethnicity (ref: White) & & $<0.0001$ \\
\hline Black & $0.80(0.72,0.88)$ & \\
\hline Hispanic & $0.64(0.54,0.75)$ & \\
\hline Other & $0.67(0.54,0.84)$ & \\
\hline Education level (ref: high school or less) & $0.82(0.76,0.89)$ & $<0.0001$ \\
\hline Marital Status (ref: married) & & 0.703 \\
\hline Never married & $0.91(0.82,1.01)$ & \\
\hline Divorced/widowed & $0.90(0.82,0.98)$ & \\
\hline Housing instability ever & $0.86(0.79,0.93)$ & $<0.0001$ \\
\hline Annual income (ref: <\$11,999) & & $<0.0001$ \\
\hline$\$ 12,000-\$ 49,999$ & $0.81(0.75,0.88)$ & \\
\hline$\geq \$ 50,000$ & $0.63(0.51,0.77)$ & \\
\hline Any cancer ${ }^{a}$ & $1.83(1.69,1.98)$ & $<0.0001$ \\
\hline Pain interference $^{a}$ & $1.15(1.06,1.25)$ & 0.001 \\
\hline \multicolumn{3}{|l|}{ HIV and clinical factors } \\
\hline CD4+ cell count $(\text { per } 100)^{a}$ & $0.92(0.91,0.94)$ & $<0.0001$ \\
\hline Virally suppressed $(\text { ref: }>=400 \operatorname{copies} / \mathrm{mL})^{\mathrm{a}}$ & $0.52(0.48,0.57)$ & $<0.0001$ \\
\hline HCV positive ${ }^{a}$ & $1.34(1.23,1.46)$ & $<0.0001$ \\
\hline \multicolumn{3}{|l|}{ Prescribed medications } \\
\hline Antidepressant duration (ref: none) ${ }^{a}$ & $1.04(0.92,1.18)$ & 0.105 \\
\hline
\end{tabular}




\begin{tabular}{|c|c|c|}
\hline Short-term & $1.08(0.99,1.18)$ & \\
\hline Long-term & & \\
\hline Gabapentinoid duration (ref: none) $^{a}$ & & 0.057 \\
\hline Short-term & $1.06(0.89,1.25)$ & \\
\hline Long-term & $1.12(0.99,1.28)$ & \\
\hline $\begin{array}{l}\text { Benzodiazepine, current } \\
\text { prescription(ref:none) }\end{array}$ & & 0.025 \\
\hline Short-term & $1.09(0.93,1.27)$ & \\
\hline Long-term & $1.15(1.00,1.27)$ & \\
\hline Substance use & & \\
\hline Current smoker ${ }^{a}$ & $1.50(1.35,1.68)$ & $<0.0001$ \\
\hline Unhealthy alcohol use ${ }^{a}$ & $0.95(0.87,1.05)$ & 0.357 \\
\hline $\begin{array}{l}\text { Self-reported opioid use trajectory group } \\
\text { (ref: stable, infrequent use) }\end{array}$ & & 0.097 \\
\hline No lifetime use & $1.16(1.05,1.28)$ & \\
\hline Escalating use & $1.09(0.96,1.23)$ & \\
\hline De-escalating use & $1.39(1.20,1.61)$ & \\
\hline
\end{tabular}

Notes: Bolding indicates a p-value $<0.05$.

a Time-updated variables 
Supplemental Table 4. Cause of death for the 1,400 participants living with HIV and engaged in care who died over the 10-year study period (n, \%).

\begin{tabular}{|c|c|c|c|c|c|c|c|c|c|c|}
\hline $\begin{array}{l}\text { Self-reported } \\
\text { opioid trajectory } \\
\text { group }\end{array}$ & \multicolumn{10}{|c|}{ Cause of death } \\
\hline & HIV & $\begin{array}{c}\text { Other } \\
\text { Infection }\end{array}$ & Cancer & CVD & Respiratory & Liver & Renal & Diabetes & Unnatural & Other \\
\hline No lifetime use & $108(39.0 \%)$ & $8(2.9 \%)$ & $55(19.9 \%)$ & $56(20.2 \%)$ & $8(2.9 \%)$ & $0(0 \%)$ & $5(1.8 \%)$ & $6(2.2 \%)$ & $18(6.5 \%)$ & $13(4.7 \%)$ \\
\hline $\begin{array}{l}\text { Stable, } \\
\text { infrequent use }\end{array}$ & $366(41.5 \%)$ & $36(4.1 \%)$ & $137(15.5 \%)$ & $141(15.9 \%)$ & $32(3.6 \%)$ & $20(2.3 \%)$ & $12(1.4 \%)$ & $10(1.1 \%)$ & $71(8.0 \%)$ & $58(6.6 \%)$ \\
\hline Escalating use & $41(35.0 \%)$ & $5(4.3 \%)$ & $28(23.9 \%)$ & $20(17.1 \%)$ & $3(2.6 \%)$ & $2(1.7 \%)$ & $1(0.9 \%)$ & $1(0.9 \%)$ & $7(5.9 \%)$ & $9(7.7 \%)$ \\
\hline $\begin{array}{l}\text { De-escalating } \\
\text { use }\end{array}$ & $55(44.7 \%)$ & $6(4.9 \%)$ & $14(11.4 \%)$ & $19(15.5 \%)$ & $4(3.3 \%)$ & $4(3.3 \%)$ & $1(0.8 \%)$ & $0(0 \%)$ & $11(8.9 \%)$ & $9(7.3 \%)$ \\
\hline $\begin{array}{l}\text { Total study } \\
\text { population }\end{array}$ & $570(40.7 \%)$ & $55(3.9 \%)$ & $234(16.7 \%)$ & $47(3.4 \%)$ & $26(1.9 \%)$ & $19(1.4 \%)$ & $19(1.4 \%)$ & $17(1.2 \%)$ & $107(7.6 \%)$ & $89(6.4 \%)$ \\
\hline
\end{tabular}

Notes: CVD- cardiovascular death. 
Supplemental Figure 1. VACS Index 2.0 score trajectories among 3,658 participants with HIV and engaged in care. Dashed lines represent estimated trajectories; solid lines represent empirical averages. Time points are based on the average time since baseline for each of the seven waves of surveys from 2002 to 2018.

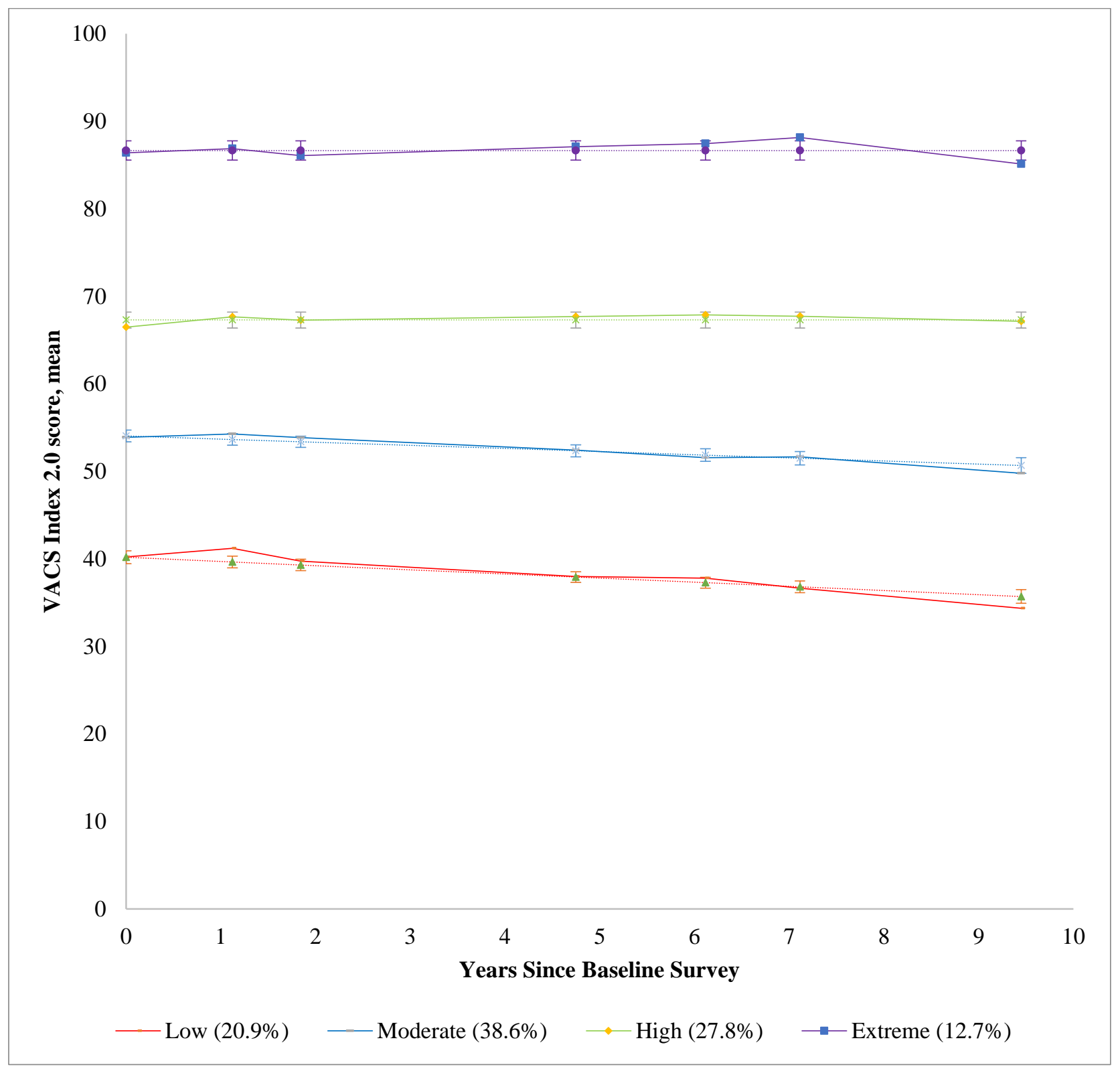


Supplemental Figure 2. Proportion of study population reporting a) exclusive prescribed opioid use, b) exclusive heroin use, or c) combined prescribed opioid and heroin use by frequency of use over each survey wave. ${ }^{a}$
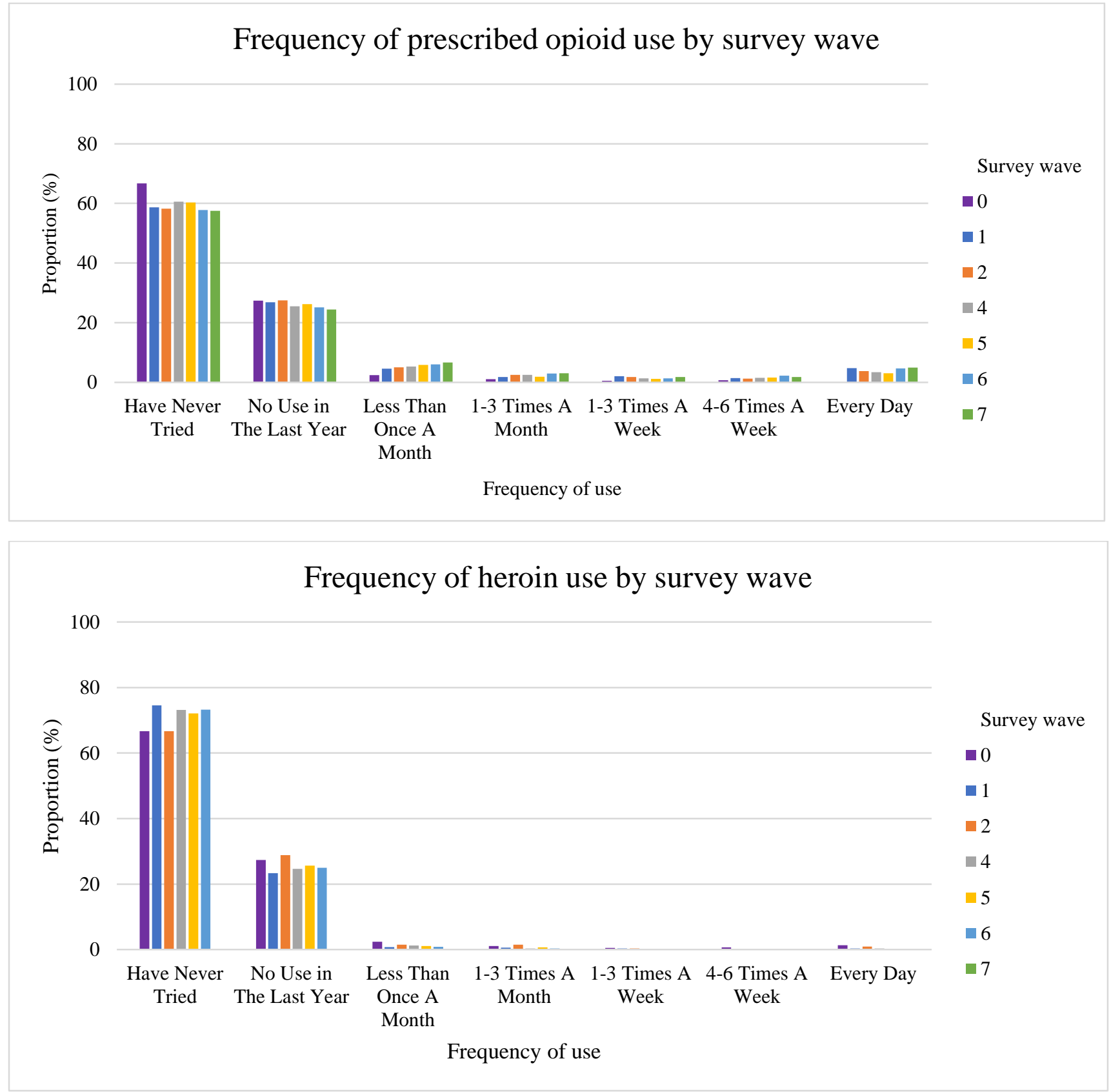


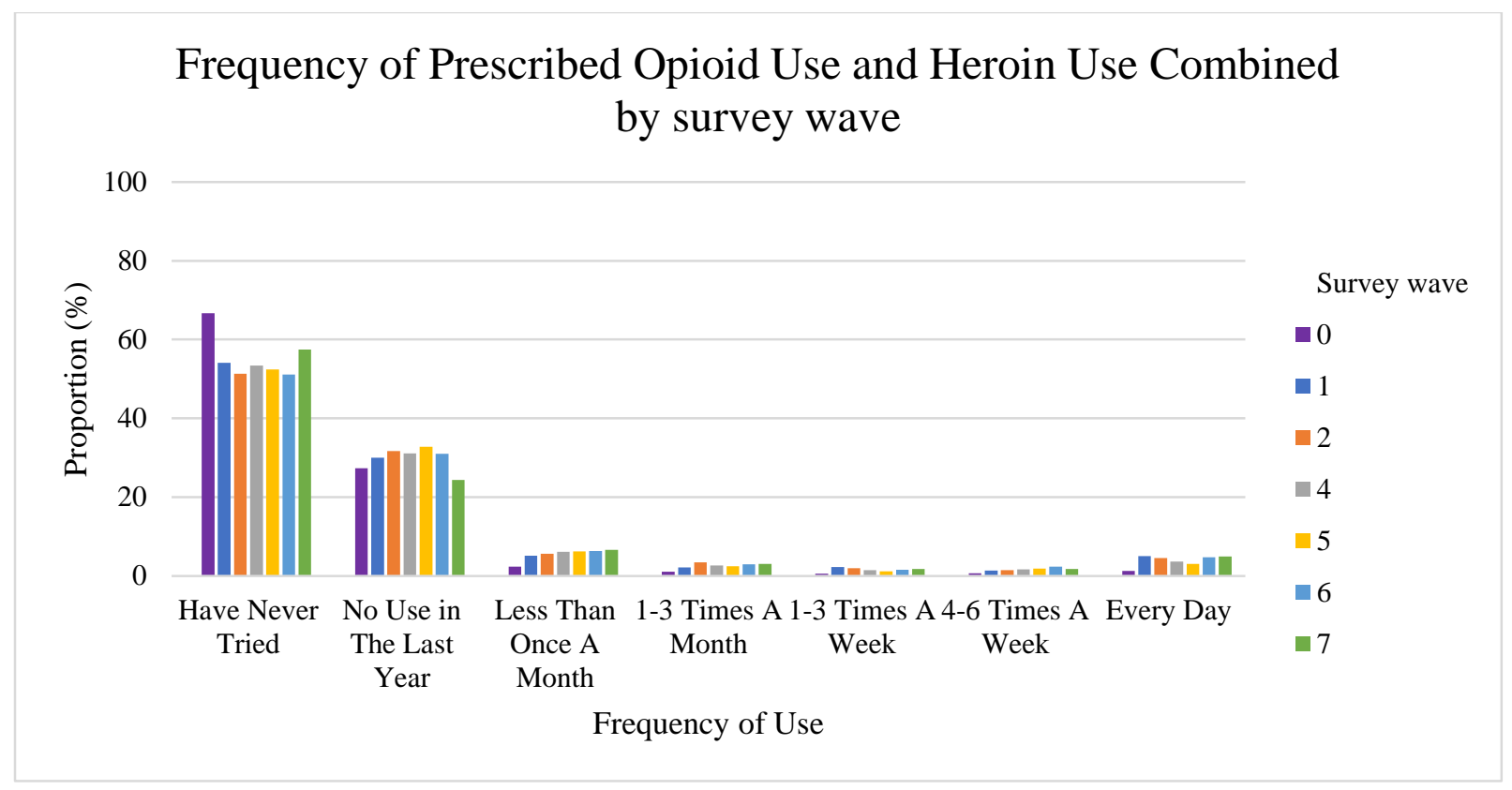

${ }^{a}$ Survey wave 3 is not included as opioid use was not assessed in the same manner as the other surveys. 